\title{
REVIEW
}

Open Access

\section{Physical activity and sedentary time of youth in structured settings: a systematic review and meta-analysis}

\author{
Rafael M. Tassitano ${ }^{1 *} \mathbb{D}$, R. Glenn Weaver ${ }^{2}$, Maria Cecília M. Tenório ${ }^{1}$, Keith Brazendale ${ }^{3}$ and Michael W. Beets ${ }^{2}$
}

\begin{abstract}
Background: Structured settings, such as school, childcare, afterschool programs, summer camps, and physical activity/sport programs are crucial to promoting physical activity (PA) opportunities and reducing sedentary (ST) for children and adolescents. However, little is known about how much PA and ST children and adolescents accumulate in structured settings. The aim of this study is to conduct a systematic review and meta-analysis of the absolute amount of time youth spend physically active and sedentary in different structured settings (Prospero number: 42018111804).

Methods: Observational and experimental/quasi-experimental studies (baseline data only) with full-text available, written in English and published in a peer-reviewed journal, reporting the total amount of objectively measured PA (light, moderate, vigorous, and/or total physical activity) and/or time spent ST during structured settings among youth (3 to 18 years) were eligible. Adjusted meta-analysis was conducted to estimate the pooled mean of time spent in PA and ST, by settings and sex.
\end{abstract}

Results: A total of 187 studies (childcare $n=60$; school $n=91$; afterschool programs $n=14$; summer camp $n=4$; and Physical activity/ sport programs $n=18$ ) from 30 countries (47.9\% United States), representing 74,870 youth (mean age 8.6 years old) were included. Overall, there was a high variation between studies in outcomes and settings. The meta-analyses revealed, on average, youth spend 221.8 minutes (36.7 min/hour) in ST and 32.1 minutes $(5.1 \mathrm{~min} /$ hour) in MVPA during childcare hours, and 223.9 minutes (36.7 min/hour) in ST and $27.8 \mathrm{~min}$ (4.4 min/hour) in MVPA at school. Relatively, youth are engaged in more MVPA in afterschool programs (11.7 min/hour), PA/ sport programs (20.9 min/hour), and summer camps (6.4 min/hour), when compared to childcare and school.

Conclusion: Total PA accumulated during childcare and MVPA accumulated during schools hours were close to recommendations, despite high proportion of ST. Afterschool programs, summer camp and PA/ sport programs are important settings that can contribute to daily PA and reduced ST. Ensuring all youth have access to these structured settings may be an important step forward for public health.

Keywords: Physical Activity, Sedentary time, Youth, Structured settings

\footnotetext{
* Correspondence: rafael.tassitano@ufrpe.br

${ }^{1}$ Department of Physical Education, Federal Rural University of Pernambuco,

SN Dom Manoel de Medeiros St, Recife, PE 52171-900, Brazil

Full list of author information is available at the end of the article
}

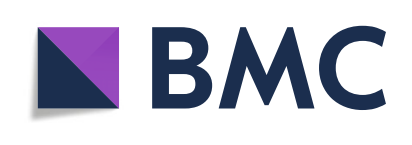

(c) The Author(s). 2020 Open Access This article is licensed under a Creative Commons Attribution 4.0 International License, which permits use, sharing, adaptation, distribution and reproduction in any medium or format, as long as you give appropriate credit to the original author(s) and the source, provide a link to the Creative Commons licence, and indicate if changes were made. The images or other third party material in this article are included in the article's Creative Commons licence, unless indicated otherwise in a credit line to the material. If material is not included in the article's Creative Commons licence and your intended use is not permitted by statutory regulation or exceeds the permitted use, you will need to obtain permission directly from the copyright holder. To view a copy of this licence, visit http://creativecommons.org/licenses/by/4.0/ The Creative Commons Public Domain Dedication waiver (http://creativecommons.org/publicdomain/zero/1.0/) applies to the data made available in this article, unless otherwise stated in a credit line to the data. 


\section{Introduction}

Health benefits related to regular engagement in physical activity (PA) and reducing sedentary time (ST) during childhood and adolescence are well documented [1-4]. Despite that, most youth around the world do not meet recommendations for PA [5-7], and significant declines in PA have been observed as youth age [8-10], and as a consequence ST increases $[8,9,11]$. Thus, promoting regular opportunities for daily PA engagement and reduced ST during childhood and adolescence continues to be a significant public health challenge.

Structured settings (i.e. school, childcare, afterschool programs, summer camps, and $\mathrm{PA} /$ sport programs) are defined as pre-planned, segmented, and adult supervised environments [12], and are the focus of most studies concerned with increasing PA in youth [1318]. The focus on structured settings makes sense for several reasons. First, almost all children and adolescents spend a large proportion of their waking time in these setting on most days and months of the year $[19,20]$. Second, structured settings typically have the infrastructure and resources in place to promote PA and reduce ST. Finally, structured settings have broad reach with most children attending one or more structured setting most days of the week (e.g., day/ childcare, schools).

However, little is known about how much PA and ST children accumulate in structured settings. While systematic reviews of PA and ST in childcare [21-23], school [15], and afterschool [16] have been published, none have identified the amount of time youth spend in PA and/or ST while attending these settings. Other reviews have focused on the time children are activity during specific segments of the school day, such as physical education class [24, 25], school playtime [26] and recess [27].

Understanding the amount of PA and ST children accumulate while attending structured settings is a crucial first step for designing more effective interventions and can help to identify which structured settings should be targeted for intervention in order to promote PA and reduce ST. Past systematic reviews are limited because they focus on total daily PA or ST [15, 21-23] without identifying the contribution of the structured setting to these estimates of PA and/or ST, were limited to specific behavior or intensity of PA [15], were largely based on subjective measures of PA and/or ST [16], and/or did not meta-analytically synthesize the findings [21-23]. In light of these limitations, the aim of this study is to conduct a systematic review and meta-analysis to summarize the amount of PA (i.e., minutes of light, moderate, vigorous, MVPA and total PA) and ST that youth accumulate while attending structured settings.

\section{Methods}

The present systematic review and meta-analysis is registered in International Prospective Register of Ongoing Systematic Reviews (PROSPERO) under the number CRD 42018111804 and reported in accordance with the Preferred Reporting Items for Systematic Reviews and Meta-Analysis (PRISMA) statement [28] (Additional file 1) and Meta-analysis of Observational Studies in Epidemiology guidelines (MOOSE) [29]. All authors agreed to the protocol before starting the search.

Observational and experimental/quasi-experimental studies (only baseline data) with available full-text, written in English and published in a peer-reviewed journal were included. Studies reporting the total amount in minutes of any PA intensity (i.e. light, moderate, vigorous or combined) and /or ST measured by objective wearable device (i.e., accelerometer, and heart rate monitor) during a structured setting among youth aged 3 to 18 years were eligible. Studies with children or adolescents in clinical settings, with disabilities, and /or institutionalized were excluded. A structured setting was defined as a context that provides a pre-planned, segmented and adult supervised component(s) (i.e. childcare, school, afterschool program, summer camp, PA/ sport program) [12]. A context-specific definition of each structured setting is presented below:

Childcare: Structured, adult supervised setting that cares for children (i.e., typically 3-5 years) as a service for working parents, and operates at a school, home, or center during weekdays, and provides a variety of different pre-planned, segmented activities for children.

School: Formal educational institution regulated by educational policies and agencies with compulsory activities during segmented times (typically on weekdays) throughout an academic year (typically 9 months a year).

Afterschool program: Community-based program that takes place immediately after regular school day and available daily throughout the academic year (Monday through Friday); and provides a combination of scheduled activities, which commonly include a snack, homework assistance/tutoring, enrichment activities, and opportunities for children to be physically active [30].

Physical activity and/or sport programs: Pre-planned, segmented, and adult supervised program with a singular focus on a specific PA or sport (i.e. soccer, dance, baseball, netball, flag football) delivered in a single day session or multiple day sessions during a week throughout the year. Programs typically consist of practices and formal competitions. 
Summer day camp: No residential or sleepover programs that serve school-aged children as a service for working parents operating during summer vacation from school and provide a variety of pre-planned, segmented activities such as PA/sports, art, and/or academics [31].

The first author (RMT) conducted the search from October 2018 to February 2019 using four electronic databases: (1) MEDLINE via PubMed, (2) SCOPUS, (3) Web of Science, and (4) Cochrane. Four groups of search terms (Outcome, Structured Setting, Measure, Population) were combined using Boolean operators (Additional file 2).

The search results were imported into EndNote X7 (Thompson Reuters, San Francisco, CA, USA), and conducted the following steps: 1) All duplicate studies were removed. 2) Titles and abstracts were screened by two independent reviewers (RMT, MCMT) to identify potential articles based on the review question. 3) Studies that did not meet the eligibility criteria were removed. 4) Full text papers of potentially eligible studies were assessed. 5) The references of all included studies were reviewed to identify additional studies. 6) Consensus on all fulltext papers excluded was reached via weekly group discussion with all authors (RMT, RGW, MCMT, KB, and MWB). Information about the article (title, year of publication, and authors), data collection (country, and global region), structured settings (childcare, school, afterschool program, summer camp, sport program), sample information (sample, sex, age, race, and socioeconomic status), protocol measure (manufactures, and data reduction procedures), PA (light, moderate, vigorous and total PA), and ST were extracted and entered into a custom Excel spreadsheet created for this study. For studies that provided other metric (i.e. min/ hour or percent) and wear time during attendance, the total amount in minutes was calculated. Studies using only a proxy reporting procedure only (i.e. the length of setting attendance) were excluded. If necessary, the authors of included studies were contacted by e-mail to provide necessary additional information.

For analysis, when studies reported mean age the nearest year was extracted. Where age was not reported, grade level was used to infer the age [32]. Where necessary standard deviations were calculated from confidence intervals $(95 \% \mathrm{CI})$, standard errors (SE), etc. based on Cochrane handbook guidelines [33]. When standard deviation, $95 \% \mathrm{CI}$, or $\mathrm{SE}$ were not reported, the standard deviation (SD) was estimated by predicting the sampleweighted coefficient of variance for each outcome of all studies in each setting [32] and computing the standard deviation using this estimate.

The risk of bias was assessed using a tool (Additional file 3) developed for the systematic review, and was created based on the moderators used in the meta- regression, and previous systematic reviewers [24, 25]. The tool consisted of 11 item covering study (i.e. design), sampling, structured setting, objective-measure protocol, and report outcomes, and was created based on the covariates used in the adjusted model of the meta-analysis. Each criteria was evaluated by two independent reviewers and scored as "presented and adequately described" (yes $=2$ ), "not clear described or presented" (yes, partially $=1$ ), or "not reported" $($ no $=0)$, and the final scored ranged between 0 to 22. A third reviewer was consulted if there is no consensus between the first two reviewers.

\section{Statistical analyses}

Studies that presented mean and standard deviation of PA and/or ST reported minutes were included in the Meta-Analysis. Studies that reported the outcome through other metrics (e.g. percent (\%), total minute by weekday in structured setting) were included in the analyses if they provided enough information to calculate the daily minutes accumulated in the setting of interest. Data were distilled separately for each structured setting.

The meta-analyses were performed in R (http://cran.rproject.org) using the robumeta, metafor and dplyr packages. Adjusted pooled means were calculated to estimate the absolute (minutes) and relative (min/hour) amount of ST and PA that children/ adolescents accumulated in each structured setting using random-effects models. Minute by hour of PA and ST was estimated by dividing the total wear time by the mean PA and ST estimate. Sex, age, sample size, study design, global region, accelerometer brand, weartime, cut-point, and risk of bias were used as covariates in the models for all outcomes and SS when appropriate and possible. The $\mathrm{I}^{2}$ index was used to identify the heterogeneity considering values of $25 \%, 50 \%$ and $75 \%$ to represent low, moderate or high, respectively [33]. Additionally, due to the variability between studies meta-regression analyses were conducted to verify each potential moderators by outcome and structured settings.

\section{Results}

A total of 5,026 records were found, and after excluding duplicate articles and those that did not meet the inclusion criteria, 187 studies were included in the qualitative synthesis. For the meta-analysis the summer camp setting were excluded due the few included studies, and all other studies from childcare, school, afterschool and physical activity/sports programs were included for the analyses (see Figure 1). Considering the structured settings, $48.7 \%$ of the studies were conducted in schools $(n=91), 32.1 \%$ in childcare $(n=60)$, $9.6 \%$ in sport programs $(n=18), 7.5 \%$ in afterschool programs $(n=14)$, and $2.1 \%$ in summer camps $(n=4)$. 
A summary of the descriptive characteristics (i.e. author, year of publication, global region, study design, sample size, sex, age, device brand, cut-point, and risk of bias) by structured setting are presented in the Table 1. The descriptive characteristics of all included studies are presented in Table 1s. General information about the measure of PA and ST (i.e. measure protocol, sample size, and average of valid wear-time during setting) and outcomes (e.g. mean and SD of ST, LPA, MPA, VPA, MVPA and TPA) are presented in Table 2s. The heterogeneity $\left(\mathrm{I}^{2}\right)$ of structured settings and outcomes ranged between $54.4 \%$ to $>90 \%$. Adjusted pooled mean (absolute and relative) estimates are presented in Table 2, considering the PA level and ST accumulated during attendance by structured settings and sex. The meta-regression analyses are presented in Tables 3s, 4s, 5s, 6s.

\section{Childcare}

A total of 60 studies [11, 13, 34-91] conducted in 12 different countries from four global regions (i.e. North America, Europe, Oceania and South America) representing 14,763 children (mean age $=4.2$ years old) were identified and included. The most common design was cross-sectional [13, 34-78] and randomized controlled trials (RCT) [79-89]. The mean wear time was $371.4 \mathrm{mi}-$ nutes (approx. 6:11 hours) during childcare hours. For the majority of the studies $(n=33)[35,36,41,42,47-50$, $54,56,58,59,61-69,73,75-78,81,86,88-90] \mathrm{PA}$ and/ or ST were measured during attendance at childcare only, while 17 measured all waking time $[34,37,38,46$, 52, 53, 55, 57, 59, 70, 71, 74, 79, 80, 85, 91], 3 studies measured PA and/or ST using 24 hour protocols [39, 45, 51], and 7 did not specifically report wear protocol [13, $38,40,43,82-84]$. A total of $75 \%$ of the studies used

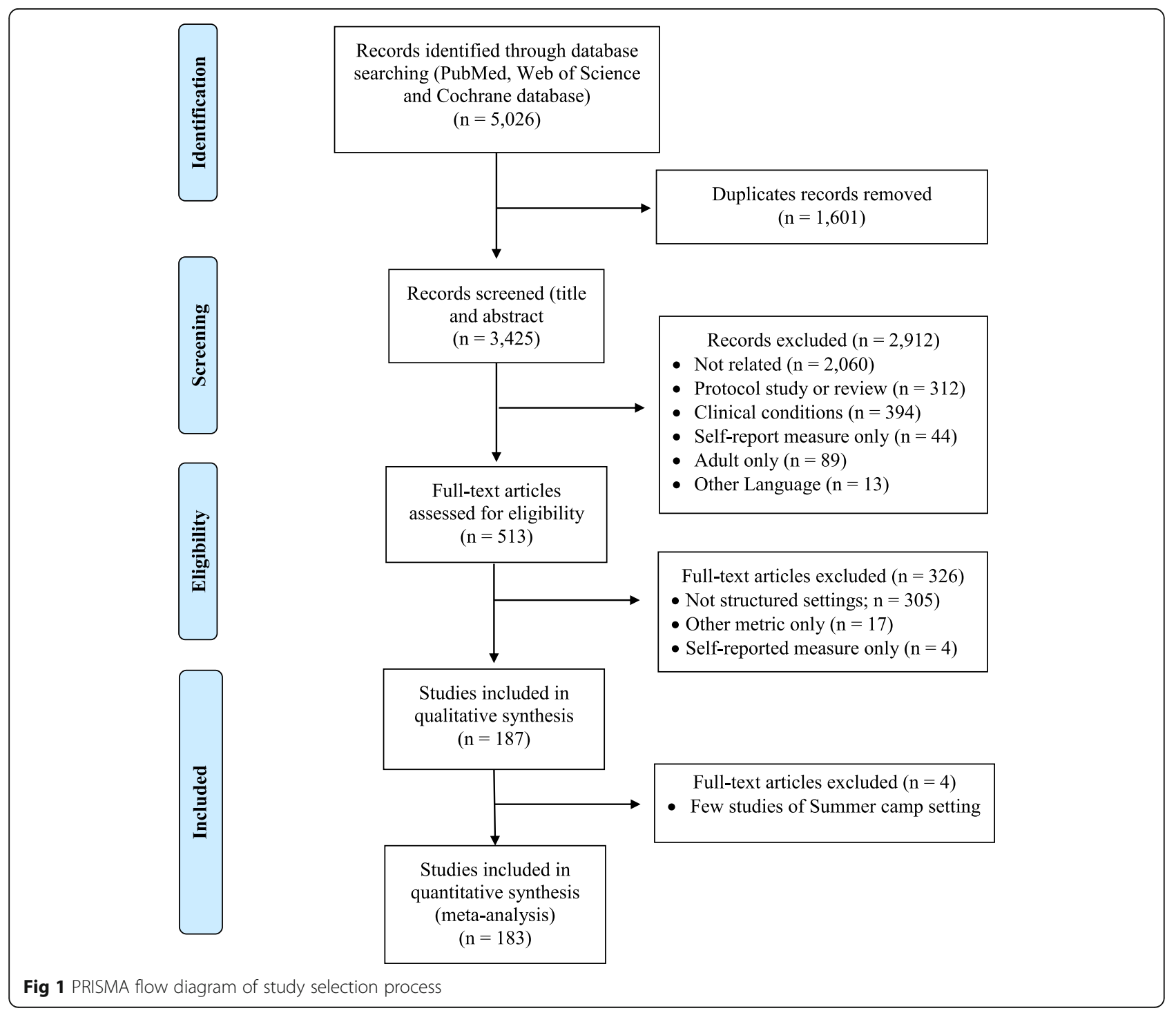


Table 1 Descriptive table of global region, study design, sample size, sex, age, device brand, cutpoints, and risk of bias by structured settings

\begin{tabular}{|c|c|c|c|c|c|c|c|c|c|c|}
\hline & \multicolumn{2}{|c|}{$\begin{array}{l}\text { Childcare } \\
(n=60)\end{array}$} & \multicolumn{2}{|c|}{$\begin{array}{l}\text { School } \\
(n=91)\end{array}$} & \multicolumn{2}{|c|}{$\begin{array}{l}\text { Afterschool program } \\
(n=14)\end{array}$} & \multicolumn{2}{|c|}{$\begin{array}{l}\text { Summer Camp } \\
(n=4)\end{array}$} & \multicolumn{2}{|c|}{$\begin{array}{l}\text { Physical activity/ Sports program } \\
(n=18)\end{array}$} \\
\hline & $n$ & (\%) & $\mathrm{n}$ & (\%) & $\mathrm{n}$ & $(\%)$ & $\mathrm{n}$ & (\%) & $\mathrm{n}$ & (\%) \\
\hline \multicolumn{11}{|l|}{ Global Region } \\
\hline North America & $42^{a}$ & $(70.0)$ & $35^{\mathrm{a}}$ & $(38.4)$ & 13 & (92.9) & 4 & $(100)$ & 12 & $(66.7)$ \\
\hline Europe & $10^{\mathrm{a}}$ & (16.6) & 40 & $(43.9)$ & -- & -- & -- & -- & 4 & $(22.2)$ \\
\hline Oceania & $7^{a}$ & $(11.7)$ & 10 & $(11.1)$ & 1 & (7.1) & - & - & 2 & $(11.1)$ \\
\hline South America & 1 & $(1.7)$ & 1 & $(1.1)$ & - & - & - & - & - & - \\
\hline Asia & -- & -- & 5 & $(5.5)$ & -- & -- & -- & -- & -- & -- \\
\hline Africa & -- & -- & -- & -- & -- & -- & -- & -- & -- & -- \\
\hline \multicolumn{11}{|l|}{ Study design } \\
\hline Cross-sectional & 46 & $(76.7)$ & 60 & $(65.9)$ & 10 & $(71.5)$ & 4 & $(100)$ & 17 & $(94.4)$ \\
\hline $\mathrm{RCT}$ & 11 & (18.3) & 11 & $(12.1)$ & 2 & $(14.3)$ & -- & -- & 1 & (5.6) \\
\hline Longitudinal & 3 & $(5.0)$ & 7 & $(7.7)$ & 1 & $(7.1)$ & -- & -- & -- & -- \\
\hline Intervention & -- & -- & 8 & (8.8) & -- & -- & -- & -- & -- & -- \\
\hline Quasi-experimental & -- & -- & 4 & $(4.4)$ & 1 & $(7.1)$ & -- & -- & -- & -- \\
\hline Natural-experiment & -- & -- & 1 & $(1.1)$ & -- & -- & -- & -- & -- & -- \\
\hline Sample size $(n)$ & 14,763 & & 42,463 & & 12,021 & & 3,330 & & 2,293 & \\
\hline$<30$ & -- & -- & -- & -- & -- & -- & -- & -- & 1 & (5.6) \\
\hline $30-200$ & 31 & $(51.6)$ & 33 & $(36.3)$ & 5 & $(35.7)$ & 3 & (75.0) & 13 & $(72.2)$ \\
\hline $201-350$ & 15 & $(25.0)$ & 19 & $(20.9)$ & 2 & $(14.3)$ & 0 & (0) & 3 & $(16.6)$ \\
\hline $351-600$ & 11 & $(18.4)$ & 19 & $(20.9)$ & 2 & $(14.3)$ & 0 & $(0)$ & 0 & $(0)$ \\
\hline$>600$ & 3 & $(5.0)$ & 20 & $(21.9)$ & 5 & $(35.7)$ & 1 & $(25.0)$ & 1 & (5.6) \\
\hline Sex & & & & & & - & & & & \\
\hline Boys & 7,765 & $(52.6)$ & 18,514 & $(43.6)$ & 5,998 & $(49.9)$ & 1,825 & $(54.8)$ & 1,321 & $(57.6)$ \\
\hline Girls & 6,998 & $(47.4)$ & 23,949 & $(56.4)$ & 6,023 & $(50.1)$ & 1,505 & $(45.2)$ & 972 & $(42.4)$ \\
\hline Age (mean) & 4.2 & $(0.7)$ & 10.1 & $(2.1)$ & 8.3 & $(1.3)$ & 8.8 & $(1.4)$ & 11.6 & $(2.0)$ \\
\hline \multicolumn{11}{|l|}{ Device brand } \\
\hline Actical & $14^{\mathrm{b}}$ & (23.0) & 2 & $(2.1)$ & - & - & - & - & 1 & (5.6) \\
\hline Actigraph & 42 & $(68.9)$ & $80^{\mathrm{b}}$ & (83.5) & 14 & $(100)$ & 4 & $(100)$ & 16 & (88.8) \\
\hline Actiheart & 1 & (1.6) & -- & -- & -- & -- & -- & -- & -- & -- \\
\hline Actipal & $2^{\mathrm{b}}$ & (3.3) & $1^{\mathrm{b}}$ & $(1.0)$ & -- & -- & -- & -- & -- & -- \\
\hline Actitrainer & 1 & (1.6) & $5^{\mathrm{b}}$ & (5.3) & -- & -- & -- & -- & -- & -- \\
\hline RT3 & 1 & (1.6) & 1 & $(1.0)$ & -- & -- & -- & -- & -- & -- \\
\hline SWM & -- & -- & 1 & $(1.0)$ & -- & -- & -- & -- & -- & -- \\
\hline NL-100 & -- & -- & 1 & $(1.0)$ & -- & -- & -- & -- & -- & -- \\
\hline HJA-3501T & -- & -- & 1 & $(1.0)$ & -- & -- & -- & -- & -- & -- \\
\hline Polar & -- & -- & 1 & $(1.0)$ & -- & -- & -- & -- & 1 & (5.6) \\
\hline Geneactiv & -- & -- & 2 & $(2.1)$ & -- & -- & -- & -- & -- & -- \\
\hline RT3 & 1 & (1.6) & 1 & $(1.0)$ & -- & -- & -- & -- & -- & -- \\
\hline \multicolumn{11}{|l|}{ Cut-points ${ }^{c}$} \\
\hline Freedson & -- & -- & 8 & (8.5) & 3 & (15.8) & 2 & (25.0) & 8 & $(40.0)$ \\
\hline Trost & 1 & (1.6) & 5 & (5.3) & 1 & (5.3) & -- & -- & -- & -- \\
\hline Evenson & 5 & $(8.1)$ & 43 & $(45.7)$ & 7 & (36.8) & 1 & (12.5) & 9 & $(45.0$ \\
\hline Matthews & -- & -- & 4 & (4.3) & 4 & (21.1) & -- & -- & -- & -- \\
\hline
\end{tabular}


Table 1 Descriptive table of global region, study design, sample size, sex, age, device brand, cutpoints, and risk of bias by structured settings (Continued)

\begin{tabular}{|c|c|c|c|c|c|c|c|c|c|c|}
\hline & \multicolumn{2}{|c|}{$\begin{array}{l}\text { Childcare } \\
(n=60)\end{array}$} & \multicolumn{2}{|c|}{$\begin{array}{l}\text { School } \\
(n=91)\end{array}$} & \multicolumn{2}{|c|}{$\begin{array}{l}\text { Afterschool program } \\
(n=14)\end{array}$} & \multicolumn{2}{|c|}{$\begin{array}{l}\text { Summer Camp } \\
(n=4)\end{array}$} & \multicolumn{2}{|c|}{$\begin{array}{l}\text { Physical activity/ Sports program } \\
(n=18)\end{array}$} \\
\hline & $\mathbf{n}$ & $(\%)$ & $n$ & (\%) & $\mathbf{n}$ & (\%) & $\mathbf{n}$ & (\%) & $n$ & (\%) \\
\hline Pate & 17 & (27.4) & -- & -- & 1 & (5.3) & -- & -- & -- & -- \\
\hline Pfeiffer & 11 & $(17.7)$ & -- & -- & -- & -- & -- & -- & -- & -- \\
\hline Puyau & 1 & (1.6) & 5 & (5.3) & 2 & $(10.5)$ & 1 & $(12.5)$ & 2 & $(10.0)$ \\
\hline Van Cauwenberghe & 7 & (11.3) & -- & -- & -- & -- & -- & -- & -- & -- \\
\hline Treuth & -- & -- & 4 & $(4.3)$ & -- & -- & 1 & $(12.5)$ & 1 & (5.0) \\
\hline Sirard & 14 & (22.6) & -- & -- & -- & -- & -- & -- & -- & -- \\
\hline Troiano & -- & -- & 1 & $(1.1)$ & -- & -- & 1 & $(12.5)$ & -- & -- \\
\hline Other & 6 & $(9.7)$ & 24 & (25.5) & 1 & $(5.3)$ & 2 & $(25.0)$ & -- & -- \\
\hline Risk of bias (mean) & 19.1 & $(1.7)$ & 18.1 & (2.3) & 20.5 & $(1.7)$ & 18.6 & (1.6) & 19.7 & (1.4) \\
\hline \multicolumn{11}{|l|}{ Risk of bias } \\
\hline$\leq 18$ & 20 & (33.3) & 45 & $(49.4)$ & 2 & $(14.3)$ & 8 & $(13.3)$ & 1 & $(25.0)$ \\
\hline $19-20$ & 27 & $(45.0)$ & 36 & (39.6) & 3 & $(21.4)$ & 7 & $(11.7)$ & 2 & $(50.0)$ \\
\hline$\geq 21$ & 13 & (21.7) & 10 & $(11.0)$ & 9 & $(64.3)$ & 3 & $(5.0)$ & 1 & $(25.0)$ \\
\hline
\end{tabular}

${ }^{a}$ Study with sample from two different countries.

b Two different devices were used in the same study.

c Based on studies that reported at least one cut-point.

Actigraph accelerometers and $23 \%$ used the Actical accelerometers. A variety of cut-points were used with the most frequently used being Pate $(2004,2006)[34,37,40$, $50-52,55,57,59,62,64,67,78,82-86]$, Sirard (2001, 2005) $[13,36,38,43,49,53,56,60,61,65,68]$, Pfeiffer (2006) [39, 41, 66, 69-71], Van Cauwenberghe (2011) $[36,38,58,63,72,74,88]$, and Evenson (2008) [44, 52, $54,73,78]$.

The meta-analyses indicated that children spend about 221.8 minutes or $36.7 \mathrm{~min} /$ hour of their time in ST and 32.1 minutes or $5.1 \mathrm{~min} /$ hour in MVPA (all cut-points) during attendance. Difference on estimates were found comparing the cut-points, where higher estimates was found on Pate cut-point (49.3 Minutes or $7.9 \mathrm{~min} /$ hour) and the lowest on Pfeiffer cut-point (24.2 minutes or 3.5 $\mathrm{min} /$ hour) (Table 2). The meta-regression analysis have indicated that 9 of 12 models were significant and the explained variance ranged between 18.2\% (ST min/hour estimate) to $60.6 \%$ (ST minute estimate). The direction and magnitude varied between outcomes and variables (Table 3s.).

Figures 2a-c and Fig. 3a-c indicate the estimated ST and MVPA min/hour by age from studies that provide the mean wear time during childcare. Estimates of MVPA $\mathrm{min} /$ hour decreased as children age in studies that provide girl and boy specific estimates. For boys MVPA decreased from $9 \mathrm{~min} /$ hour at age 3 to $5 \mathrm{~min} /$ hour at age 5 , while for girls MVPA decreased from $7 \mathrm{~min} /$ hour to $4 \mathrm{~min} /$ hour. However, an inverted "U" pattern was observed for studies that combined estimates of MVPA for boys and girls. For studies that provide ST estimates for girls and boys separately, increases in ST from 3 to 4 years old and then a leveling off between 4 and 5 years old was observed. Studies that combine boys and girls show that ST increased steadily as children aged.

\section{School}

A total of 91 studies [91-181] conducted in 29 countries from all global regions representing 42,463 youth (mean age $=10.1 \pm 2.1$ ) were included. Although all global regions are represented, only one study from South America [92] and five from Asia were found [93-97], while Europe [91, 97-134] (45.9\%) and North America [135177] are the most represented regions. Similar to childcare, cross-sectional, and RCT [112, 124, 144, 145, 157, $167,168,174-177]$ were the most common design. The mean wear time was 362.8 minutes (approx.:6:04 hours) during school hours. In 50 studies, the measure of PA and/or ST occurred during all waking time [91, 95, 96, 98, 99, 103-111, 113, 115-118, 120-126, 128, 130-134, $140,141,143,150,151,155,160,161,163,168,171$, $176,178-180$ ] while in 20 studies during school hours were measured $[92,93,97,114,136-139,152,153,156$, 159, 164-167, 172, 174], 11 studies measured using 24hour protocols $[101,119,127,154,159,169,170,175$, 181 ], and 11 did not specifically report wear protocols [94, 102, 104, 112, 135, 142, 145, 148, 149, 157, 173]. A total of $86.9 \%$ of the studies used Actigraph 
Table 2 Summary of adjusted pooled mean in minutes and min/hour estimates of physical activity and sedentary time by structured settings

\begin{tabular}{|c|c|c|c|c|c|c|c|c|c|c|c|}
\hline Settings & Outcomes & k & e & $\begin{array}{l}\text { Adjusted pooled } \\
\text { mean (min) }\end{array}$ & SE & Lower & Upper & $\begin{array}{l}\text { Adjusted } \\
\text { pooled mean } \\
(\mathrm{min} / \mathrm{h})\end{array}$ & SE & Lower & Upper \\
\hline \multirow[t]{10}{*}{ Childcare } & Sedentary time & 44 & 86 & 221.8 & 9.7 & 196.1 & 247.5 & 36.7 & 2.0 & 32.5 & 40.9 \\
\hline & Light physical activity & 30 & 64 & 82.0 & 5.0 & 70.8 & 93.2 & 13.5 & 1.0 & 11.1 & 15.4 \\
\hline & Moderate physical activity & 13 & 24 & 19.7 & 4.1 & 8.1 & 31.1 & 3.6 & 0.8 & 1.4 & 5.9 \\
\hline & Vigorous physical activity & 17 & 36 & 12.6 & 2.2 & 7.4 & 17.8 & 2.6 & 0.5 & 1.5 & 3.8 \\
\hline & $\begin{array}{l}\text { Moderate to vigorous physical } \\
\text { activity (All) }\end{array}$ & 46 & 90 & 32.1 & 2.3 & 27.4 & 36.8 & 5.1 & 0.3 & 4.4 & 5.9 \\
\hline & $\begin{array}{l}\text { Moderate to vigorous physical } \\
\text { activity (Pate) }\end{array}$ & 15 & 32 & 49.3 & 3.1 & 42.0 & 56.6 & 7.9 & 0.6 & 6.5 & 9.3 \\
\hline & $\begin{array}{l}\text { Moderate to vigorous physical } \\
\text { activity (Pfeiffer) }\end{array}$ & 9 & 19 & 24.2 & 2.4 & 12.9 & 33.6 & 3.5 & 0.4 & 1.9 & 5.3 \\
\hline & $\begin{array}{l}\text { Moderate to vigorous physical } \\
\text { activity (Sirard) }\end{array}$ & 11 & 22 & 32.0 & 8.0 & 19.5 & 47.4 & 5.5 & 0.9 & 3.0 & 7.9 \\
\hline & $\begin{array}{l}\text { Moderate to vigorous physical } \\
\text { activity (Other) }\end{array}$ & 11 & 17 & 28.8 & 3.0 & 19.1 & 38.5 & 5.1 & 0.5 & 3.8 & 6.4 \\
\hline & Total physical activity & 28 & 42 & 100.6 & 5.3 & 87.6 & 126.5 & 13.5 & 1.0 & 11.3 & 15.6 \\
\hline \multirow[t]{8}{*}{ School } & Sedentary time & 44 & 130 & 223.9 & 4.7 & 214. & 233.6 & 36.7 & 0.7 & 35.1 & 38.3 \\
\hline & Light physical activity & 29 & 59 & 114.6 & 6.1 & 99.9 & 129.4 & 18.8 & 1.1 & 16.6 & 21.6 \\
\hline & Moderate physical activity & 16 & 40 & 23.3 & 5.7 & 9.6 & 36.9 & 3.8 & 0.9 & 1.6 & 6.1 \\
\hline & Vigorous physical activity & 19 & 48 & 10.1 & 1.2 & 7.5 & 12.8 & 1.6 & 0.2 & 1.2 & 2.1 \\
\hline & $\begin{array}{l}\text { Moderate to vigorous physical } \\
\text { activity (All) }\end{array}$ & 75 & 198 & 27.8 & 1.5 & 24.6 & 31.0 & 4.4 & 0.2 & 3.9 & 4.9 \\
\hline & $\begin{array}{l}\text { Moderate to vigorous physical } \\
\text { activity (Evenson) }\end{array}$ & 39 & 89 & 24.2 & 1.2 & 21.6 & 26.7 & 3.9 & 0.2 & 3.5 & 4.3 \\
\hline & $\begin{array}{l}\text { Moderate to vigorous physical } \\
\text { activity (Other) }\end{array}$ & 36 & 109 & 29.9 & 2.7 & 24.0 & 35.6 & 4.8 & 0.4 & 3.9 & 5.7 \\
\hline & Total physical activity & -- & -- & -- & -- & -- & -- & -- & -- & -- & -- \\
\hline \multirow[t]{6}{*}{ Afterschool } & Sedentary time & 8 & 28 & 54.5 & 4.4 & 40.3 & 68.7 & 25.9 & 2.0 & 19.5 & 32.3 \\
\hline & Light physical activity & 9 & 21 & 43.3 & 3.3 & 32.6 & 54.0 & 21.5 & 1.7 & 16.0 & 26.9 \\
\hline & Moderate physical activity & 6 & 13 & 10.1 & 1.6 & 3.0 & 17.2 & 5.1 & 0.9 & 1.1 & 9.1 \\
\hline & Vigorous physical activity & 8 & 22 & 8.5 & 1.6 & 3.4 & 13.6 & 4.0 & 0.8 & 1.4 & 6.7 \\
\hline & $\begin{array}{l}\text { Moderate to vigorous physical } \\
\text { activity }\end{array}$ & 14 & 31 & 23.5 & 1.9 & 19.1 & 27.9 & 11.7 & 1.1 & 9.2 & 14.1 \\
\hline & Total physical activity & -- & -- & -- & -- & -- & -- & -- & -- & -- & -- \\
\hline \multirow{8}{*}{$\begin{array}{l}\text { Sport / Physical } \\
\text { Activity programs }\end{array}$} & Sedentary time & 16 & 38 & 11.7 & 1.5 & 8.3 & 15.2 & 11.4 & 1.7 & 7.5 & 15.3 \\
\hline & Light physical activity & 13 & 34 & 25.6 & 2.2 & 20.4 & 30.8 & 26.3 & 2.1 & 21.5 & 31.2 \\
\hline & Moderate physical activity & 12 & 33 & 12.8 & 1.3 & 10.6 & 17.0 & 12.3 & 1.4 & 9.8 & 16.7 \\
\hline & Vigorous physical activity & 13 & 33 & 8.5 & 2.2 & 4.4 & 14.6 & 7.3 & 1.9 & 3.9 & 12.7 \\
\hline & $\begin{array}{l}\text { Moderate to vigorous physical } \\
\text { activity (All) }\end{array}$ & 18 & 40 & 18.9 & 2.4 & 13.6 & 24.2 & 20.9 & 2.3 & 15.9 & 25.9 \\
\hline & $\begin{array}{l}\text { Moderate to vigorous physical } \\
\text { activity (Evenson) }\end{array}$ & 9 & 16 & 18.8 & 3.5 & 11.1 & 26.4 & 18.5 & 2.7 & 12.4 & 24.6 \\
\hline & $\begin{array}{l}\text { Moderate to vigorous physical } \\
\text { activity (Freedson) }\end{array}$ & 7 & 18 & 22.4 & 5.0 & 11.4 & 33.5 & 21.0 & 3.8 & 12.7 & 29.4 \\
\hline & Total physical activity & -- & -- & -- & -- & -- & -- & -- & -- & -- & -- \\
\hline
\end{tabular}



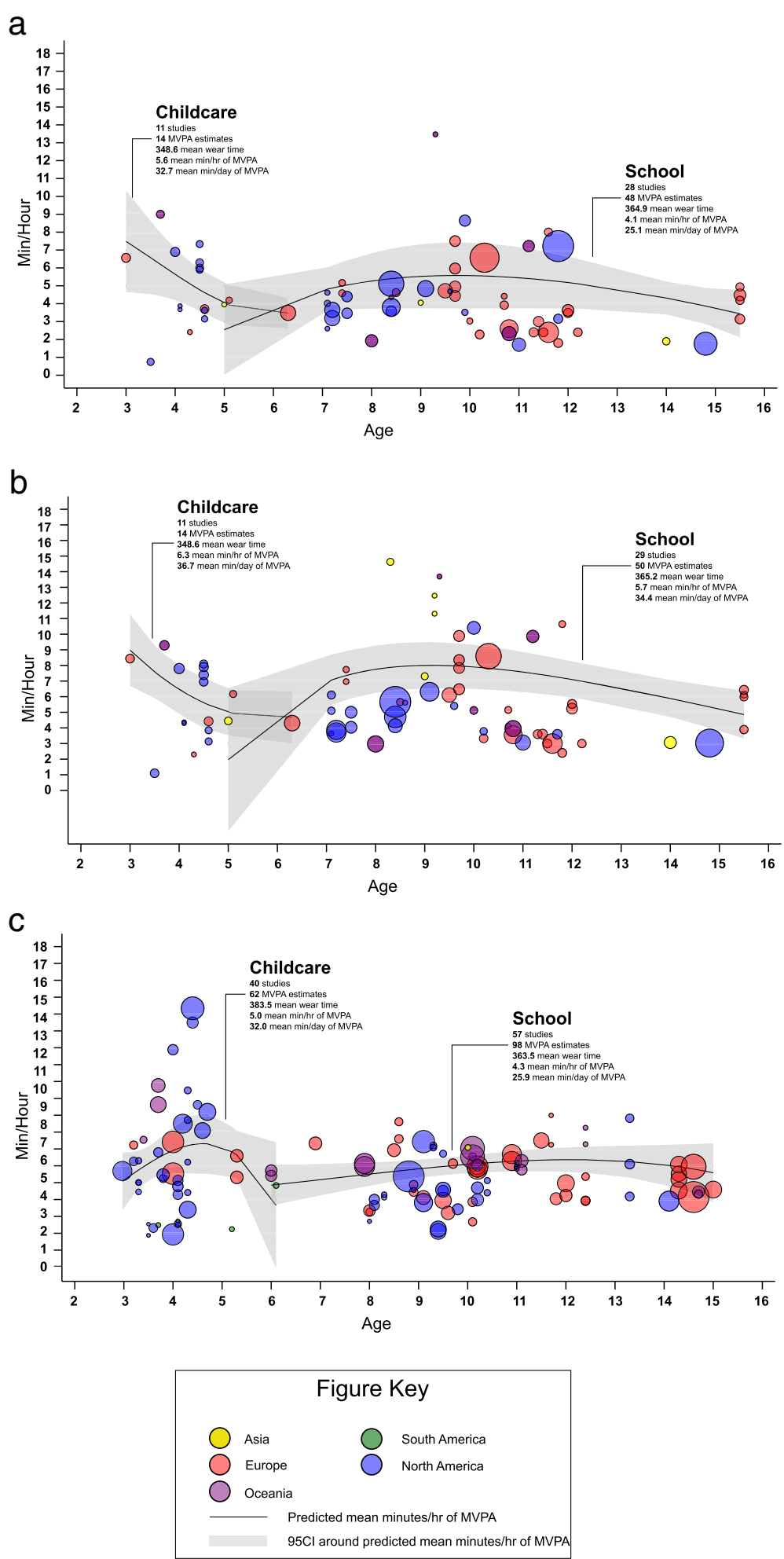

Fig 2 a-c. Scatter plot and estimated mean min/hour of moderate to vigorous physical activity by age during childcare and school. $\mathbf{a}=$ Girls studies that provide girl specific estimates of MVPA. $\mathbf{b}=$ Boys - studies that provide boy specific estimates of MVPA. $\mathbf{c}=$ Total - studies that combine boys and girls together estimates of MVPA 

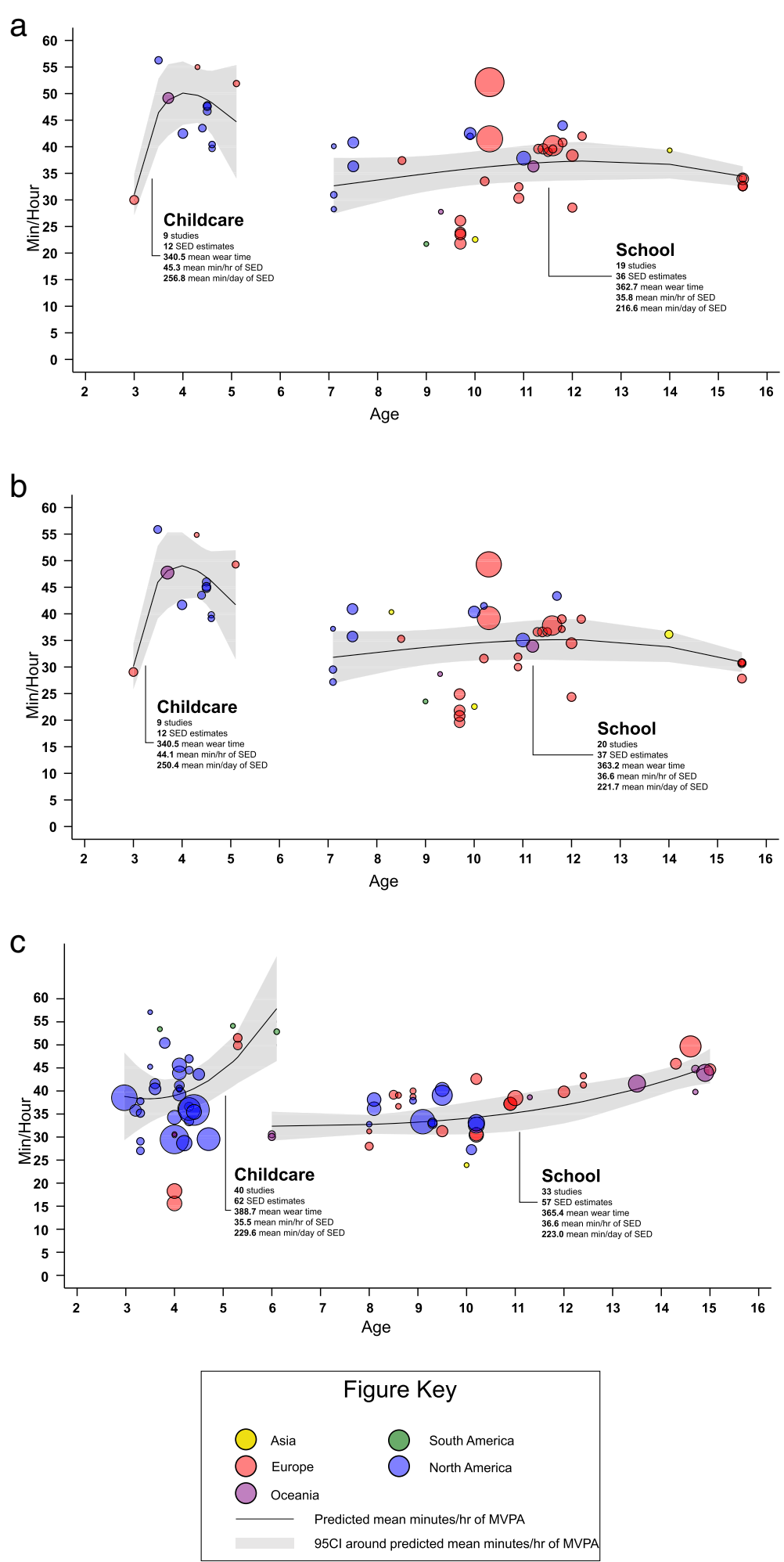

Fig 3 a-c. Scatter plot and estimated mean min/hour of sedentary time by age during childcare and school. $\mathbf{a}=$ Girls - studies that provide girl specific estimates of ST. $\mathbf{b}=$ Boys - studies that provide boy specific estimates of ST. $\mathbf{c}=$ Total - studies that combine boys and girls together estimates of ST 
accelerometers, and the most often used cut-points were Evenson (2008) [92, 96, 98-100, 103, 114, 115, 121, 123, $124,126,129,130,136-139,141-143,153,154,156$, 157, 159, 164-167, 173-177], Freedson (1998, 2005) [93, 94, 140, 144, 146, 151, 152, 168], Puyau (2002, 2004) $[105,108,117,145,178,180]$, and Treuth (2004) [122, $128,162,170]$.

The meta-analyses indicated that youth spend about 223.9 minutes or $36.7 \mathrm{~min} /$ hour of their time in ST and 27.8 minutes or $4.4 \mathrm{~min} /$ hour in MVPA (all cut-points) or 24.8 minutes and $3.9 \mathrm{~min} /$ hour considering Evenson cut-point during attendance. The meta-regression analysis have indicated that 4 of 10 models were significant and the explained variance ranged between 6.0\% (MVPA $\mathrm{min} /$ hour estimate) to $43.8 \%$ (ST minute estimate). The direction and magnitude varied between outcomes (Table 4s.).

Figures 2a-c and Fig. 3a-c indicate the estimated hourly ST and MVPA by age from studies that provide the mean wear time during school. Studies that provide boys and girls estimates separately demonstrated a similar pattern of MVPA accumulation across ages. At age 5 boys and girls spent approximately $2 \mathrm{~min} /$ hour in MVPA during school, this increased to approximately 5 $\mathrm{min}$ /hour (girls) and $7 \mathrm{~min} /$ hour (boys) by age 8 . Between 8 and 16 years a slight decreased in MVPA min/ hour was observed. Alternatively, for studies that combined boys and girls MVPA estimates MVPA min/hour was relatively stable from 6 to 15 years. For ST the flat line were observed in studies that provide estimates for each sex, while and increasing of $\mathrm{min} /$ hour in ST (30 minutes to 40 minutes) when aging among studies that combine sex.

\section{Afterschool programs}

The 14 included studies [17, 149, 156, 182-193] were conducted in only two countries, with the majority taking place in United States and the one other study conducted in Australia. The total sample size for all studies combined was 12,021 children (range 82 to 2,053 , mean age $=8.3$ years). Five studies had more than 600 children [17, 182185]. Cross-sectional studies represented the most common design [17, 156, 183, 184, 186-192], and Actigraph was the only accelerometer brand used to measure PA and ST. The majority of the studies addressed the outcomes during afterschool hours only, while one considered all waking hours in addition to activity and sedentary during afterschool hours. The mean valid wear time during attendance was 125.7 minutes per day (approx. 2:05 hours). A variety of cut-points were used with the most frequent being Freedson (2005) [189, 191, 193], Evenson (2008), and Matthews (2008) [17, 183, 185, 188].

The meta-analyses estimates indicated that youth spend about 54.5 minutes or $25.9 \mathrm{~min} /$ hour of their time in ST and 23.5 minutes or $11.7 \mathrm{~min} /$ hour in MVPA during attendance. Only 3 of 10 models of meta-regression were significant and explained $10.6 \%$ (ST $\mathrm{min}$ /hour estimate) to $52.7 \%$ (LPA minute estimate) of the variance (Table $5 \mathrm{~s}$ ).

\section{Summer camp}

All studies $(n=4)$ were conducted in the United States [31, 194-196], and three of four were published between 2017 and 2018 [31, 195, 196], using cross-sectional designs [31, 194-196] or nested quasi-experimental [31], and Actigraph accelerometers [31, 194-196]. The total sample size for all studies combined was 3,330 children (range 132 to 3,389 , mean age $=8.8$ years). All four included studies reported MVPA during summer camp hours, while only one reported ST [31] and one reported VPA [196]. The mean valid wear time during attendance was 409.0 minutes per day (approx. 6:49 hours). One study estimated MVPA using five different cut-points and the means ranged between 18.8 minutes to $50.4 \mathrm{mi}-$ nutes, or $3.3 \mathrm{~min} /$ hour to $9.0 \mathrm{~min} /$ hour [194].

\section{Physical activity / Sport programs}

A total of 18 studies [151, 197-213] from five different countries in three regions (i.e. North America, Europe and Oceania) were identified and included, representing 2,293 participants. The total valid wear time was 67.8 minutes (1:07 hour). Only one study used RCT design [197], and all other were cross-sectional [151, 198-213]. Actigraph was the lone accelerometer brand, and the most often used cut-points were Evenson (2008) [198200, 204, 206, 208, 210], and Freedson (2005) [151, 201, 203-205, 207, 211, 213]. The meta-analyses estimates indicated that youth spend about 11.7 minutes or 11.4 min/hour of their time in ST and 18.9 minutes or 20.9 min/hour in MVPA (all cut-point) during attendance. The meta-regression analyses revealed that 8 of 10 models were significant and explained 26.4\% (ST min/ hour estimate) to $68.1 \%$ (LPA minute estimate) of the variance (Table $6 \mathrm{~s}$ ).

\section{Discussion}

The purpose of this systematic review and meta-analyses was to estimate the amount of PA and ST that youth accumulate during different structured settings (i.e., childcare, school, afterschool programs, summer camps and sports programs). The present study provides absolute (i.e. minutes) and relative (i.e. min/hour) estimates of PA and ST from a large sample of studies that represent different countries and regions across the world. A key finding of this study is that all structured settings provided substantial amounts of physical activity during attendance. These findings highlight the important contribution structured settings have on youth accumulation of health-enhancing physical activity. 
Historically school-based settings have been the preferred environment for promoting PA and reducing ST opportunities for children and adolescents [213-215]. As expected, the majority of the studies were conducted in school and childcare, in high income-countries, and reported MVPA. However, in recent years, the number of studies focusing on other structured settings (i.e. afterschool, summer camps and sport programs), and reporting ST and additional metrics of PA beyond MVPA during attendance has increased. This is important for two reasons. First, this indicates the relevance and importance of other structured settings for promoting PA for children and adolescents across different times of the week such as weekdays (i.e. afterschool and sports programs), and weekend days (i.e. sports programs), and during times away from school (i.e. summer camp, holiday camps). Second, the estimates of ST and PA intensity provide a better understanding of the overall 'contribution' of these structured settings to youths' ST and PA. This is valuable information for researchers and practitioners for further initiatives, programs, and policies.

Globally, the school-time estimates presented herein ( $27.8 \mathrm{~min} /$ day MVPA) are slightly below the recommendation that states youth should accumulate at least 30 minutes of MVPA during attendance [19, 20]. Considering these are mean estimates only, and despite the high methodological variability and cultural differences between studies, these data provide evidence that schools are close to providing the expected amount of MVPA during attendance. However, this does not mean that schools are reaching their potential for promoting PA. For example, in the United States, fewer public schools have adopted all components of the comprehensive school PA program [216], which calls for multiple school-related environments (e.g., before and after school time) to provide comprehensive and consistent PA programming and opportunities for youth. Moreover, the current data from the Global Matrix 3.0 indicates that $40.8 \%$ of the 49 included countries were graded $\mathrm{C}$ or $\mathrm{D}$ on school indicators for promoting PA opportunities [217]. Important to note that the observed heterogeneity was partially explained by the moderators. For MVPA estimates for example, while the variability are explained by the sex and the global region context, other variables related to the methods, such as cutpoints and risk of bias are significant in the models (i.e. absolute and relative estimates) as well.

In childcare, the current study showed TPA per hour estimates were close the $15 \mathrm{~min} /$ hour Institute of Medicine (IOM) recommendation [218], and children accumulate $55 \%$ of the daily recommended MVPA while attending ( 6 hours). Once again, this finding does not mean that all childcare settings are automatically achieving all PA recommendations. For example, childcare settings are called upon to provide a variety of indoor/ outdoor [219222], structured/organized activities [219-221], and to eliminate sitting for extended periods [219]. To date, all released guidelines for pre-school aged children [219-222] provide critical elements on PA for policy makers, educators, and childcare service, however, little is known about countries regulations, and the dissemination and implementation of any initiative in that direction maybe restricted to a few countries. For childcare, the more consistent moderator in the meta-regression was the accelerometer brand (i.e. Actigraph and Actical), which was significant for the absolute and relative metrics estimates models of ST, LPA, MVPA and TPA.

The current study indicates that the mean estimate of MVPA in afterschool settings was $23.5 \mathrm{~min} /$ day, $6.5 \mathrm{mi}-$ nutes short of the 30 minutes/day recommendation for afterschool program hours [223]. Nonetheless, afterschool programs provide children a substantial amount of MVPA. Moreover, during attendance youth spend less time sedentary $(<45 \%$ of the time), compared to childcare and school $(\sim 60 \%)$. In other words, current practice in afterschool programs provides children and adolescents with substantial amounts of PA and limits ST. Thus, afterschool programs have great potential to promote youth PA and reduce ST. Simply providing children and adolescents access to these programs may provide substantial amounts of MVPA and reduce ST.

Estimates indicated that youth accumulate 18.9 minutes in MVPA, with 8.5 minutes of this spent in VPA during PA / sport programs. Interestingly, for boy and girl estimates only, the amount of MVPA accumulated during the sessions were 28.3 and 26.4 minutes, respectively. The difference between the combined estimates versus separate boys and girl estimates are due to the type of activity. While the majority of the included studies for the combined estimate have pre-planned PA or dance [198, 199, 207, 209, 211] for boy and girl estimates included more sport activities such as soccer, basketball, and flag ball. Regardless the type of planned activity, the amount of MVPA accumulated in a lower length of time $(\sim 60 \mathrm{mi}-$ nutes), is substantial. In addition, children accumulate more daily MVPA during sports day compared non-sport day, and reduced ST by nearly 40 minutes [224].

The out-school months (e.g. vacation) has been identified as critical period associated to negative effects on youth's health due the less structured environment (e.g. lack of routine, non-supervision) that they are exposure. However, few studies examined youth's accumulation of ST and PA during summer camp programs and all included studies are from the United States [31, 194-196]. While studies indicated that youth are close to [195] or achieving more than the daily recommendations of MVPA [31, 196], the other indicated similar estimates 
when compared to a school day [194]. Thus, more studies conducted in summer camps are necessary to estimate their potential for promoting physical activity.

The major limitation is the high variability between the studies in all outcomes and structured settings (i.e. $40.6 \%$ of the included studies had low score on the risk of bias tools, and $\mathrm{I}^{2}>54.4 \%$ ). Previous systematic reviews $[22,23]$ have reported several methodological reasons that explain the variability between studies, such as differences in accelerometer cut-points, study design, inclusion criteria, measurement protocol of PA and ST, and data reduction processes. Additionally, estimates may be influenced by educational policies, length of attendance, delivery based (e.g. public/private, and church-based, school-based, family-based), and type of sport programs (e.g. competition, practice, and leisure activity), and/or cultural differences. Further studies should include descriptive information related to the structured (e.g. child attendance, start time and end time, school length duration), accelerometer protocol measure, and descriptive information about the valid data (e.g. mean wear-time, mean of valid days). Finally, the present study did not review the grey literature.

The present study also has several strengths that should be highlighted including: (a) estimated PA and ST for several well attended settings; (b) all studies provide objectively-measured estimates of $\mathrm{PA}$ and/or ST during structured setting attendance; (c) exhaustive literature search representing countries around the world. The estimates provided herein could support further policies and recommendations for PA and ST, and help to identify potential levers for intervention in structured settings across the world.

\section{Conclusions}

The present study summarized the amount of PA (i.e. light, moderate, vigorous, MVPA and total PA) and ST that youth accumulate while attending childcare, school, afterschool programs, summer camp and $\mathrm{PA} /$ sport programs. The majority of the included studies are conducted in childcare and school, and in high-income countries. Our study found that routine practice in childcare and school provide children with large quantities of PA. These findings demonstrate that interventions delivered during the childcare and school day might produce better results if they focus on reducing sedentary time rather than promoting PA. Further, future PA interventions may need to target times outside of the school and childcare day. In light of these findings, governments and public health agencies should focus efforts on providing all youth access to these structured settings for health benefit.

\section{Supplementary Information}

The online version contains supplementary material available at https://doi. org/10.1186/s12966-020-01054-y.

\section{Additional file 1 \\ Additional file 2. \\ Additional file 3. \\ Additional file 4. \\ Additional file $\mathbf{5}$. \\ Additional file 6.}

\section{Acknowledgements}

None

\section{Authors' contributions}

All authors conceived and designed the work. RMT conducted the database searches, performed data extraction and wrote the manuscript. RGW, MWB and $\mathrm{KB}$ reviewed articles in the case of disagreements. RMT and MCMT analyzed and interpreted the data with advice from RGW, MWB and KB. All authors had full access to all of the data in the study and take the responsibility for the integrity of the data and the accuracy of the data analysis. All authors contributed substantially to the article and approved the final version for submission.

Funding

No funding.

\section{Availability of data and materials}

All data generated or analyzed during this study are included in this published article.

Ethics approval and consent to participate

Not applicable.

Consent for publication

Not applicable.

\section{Competing interests}

The authors declare that they have no competing interests.

\section{Author details}

'Department of Physical Education, Federal Rural University of Pernambuco, SN Dom Manoel de Medeiros St, Recife, PE 52171-900, Brazil. ${ }^{2}$ University of South Carolina, Columbia, SC, USA. ${ }^{3}$ University of Central Florida, Orlando, FL, USA.

Received: 24 April 2020 Accepted: 9 November 2020

Published online: 04 December 2020

References

1. Poitras VJ, Gray CE, Borghese MM, Carson V, Chaput JP, Janssen I, et al. Systematic review of the relationships between objectively measured physical activity and health indicators in school-aged children and youth. Appl Physiol Nutr Metab. 2016;41(6 Suppl 3):S197-239.

2. Poitras VJ, Gray CE, Janssen X, Aubert S, Carson V, Faulkner G, et al. Systematic review of the relationships between sedentary behaviour and health indicators in the early years (0-4 years). BMC Public Health. 2017; 17(Suppl 5):868.

3. Carson V, Lee EY, Hewitt L, Jennings C, Hunter S, Kuzik N, et al. Systematic review of the relationships between physical activity and health indicators in the early years (0-4 years). BMC Public Health. 2017;17(Suppl 5):854.

4. Carson V, Hunter S, Kuzik N, Gray CE, Poitras VJ, Chaput JP, et al. Systematic review of sedentary behaviour and health indicators in school-aged children and youth: an update. Appl Physiol Nutr Metab. 2016;41(6 Suppl 3): S240-65.

5. Hallal PC, Andersen LB, Bull FC, Guthold R, Haskell W, Ekelund U, et al. Global physical activity levels: surveillance progress, pitfalls, and prospects. Lancet. 2012;380(9838):247-57. 
6. Steene-Johannessen J, Hansen BH, Dalene KE, et al. Variations in accelerometry measured physical activity and sedentary time across Europe - harmonized analyses of 47,497 children and adolescents. Int J Behav Nutr Phys Act. 2020;17:38.

7. Cooper AR, Goodman A, Page AS, et al. Objectively measured physical activity and sedentary time in youth: the International children's accelerometry database (ICAD). Int J Behav Nutr Phys Act. 2015;12:113.

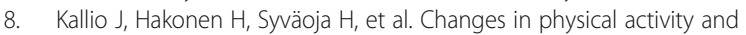
sedentary time during adolescence: Gender differences during weekdays and weekend days. Scand J Med Sci Sports. 2020:30(7):1265-75.

9. Jago R, Salway R, Emm-Collison L, Sebire SJ, Thompson JL, Lawlor DA. Association of BMI category with change in children's physical activity between ages 6 and 11 years: a longitudinal study. Int J Obes (Lond). 2020; 44(1):104-13.

10. Farooq A, Martin A, Janssen X, et al. Longitudinal changes in moderate-tovigorous-intensity physical activity in children and adolescents: A systematic review and meta-analysis. Obes Rev. 2020;21(1):e12953.

11. Carson V, Salmon J, Crawford D, Hinkley T, Hesketh KD. Longitudinal levels and bouts of objectively measured sedentary time among young Australian children in the HAPPY study. J Sci Med Sport. 2016;19(3):232-6.

12. Brazendale K, Beets MW, Weaver RG, Pate RR, Turner-McGrievy GM, Kaczynski AT, et al. Understanding differences between summer vs. school obesogenic behaviors of children: the structured days hypothesis. Int Behav Nutr Phys Act. 2017;14(1):100

13. Pate RR, Pfeiffer KA, Trost SG, Ziegler P, Dowda M. Physical activity among children attending preschools. Pediatrics. 2004;114(5):1258-63.

14. Larson N, Ward DS, Neelon SB, Story M. What role can child-care settings play in obesity prevention? A review of the evidence and call for research efforts. J am Diet Assoc. 2011;111(9):1343-62.

15. Brooke HL, Corder K, Atkin AJ, van Sluijs EM. A systematic literature review with meta-analyses of within- and between-day differences in objectively measured physical activity in school-aged children. Sports Med. 2014;44(10): $1427-38$.

16. Beets MW, Beighle A, Erwin HE, Huberty JL. After-school program impact on physical activity and fitness: a meta-analysis. Am J Prev Med. 2009;36(6):52737.

17. Beets MW, Huberty J, Beighle A, Moore JB, Webster C, Ajja R, et al. Impact of policy environment characteristics on physical activity and sedentary behaviors of children attending afterschool programs. Health Educ Behav. 2013;40(3):296-304.

18. Hills AP, Dengel DR, Lubans DR. Supporting public health priorities: recommendations for physical education and physical activity promotion in schools. Prog Cardiovasc Dis. 2015;57(4):368-74.

19. Kohl HW III, Cook HD. Committee on Physical Activity and Physical Education in the School Environment; Food and Nutrition Board; Institute of Medicine. In: Educating the Student Body: Taking Physical Activity and Physical Education to School. Washington (DC): National Academies Press (US); 2013

20. Centers for Disease Control and Prevention. Comprehensive School Physical Activity Programs: A Guide for Schools. Atlanta, GA: U.S: Department of Health and Human Services; 2013. Avaliable from: https://www.cdc.gov/ healthyschools/physicalactivity/index.htm. Accessed 20 January 2020.

21. Vanderloo LM, Martyniuk OJ, Tucker P. Physical and Sedentary Activity Levels Among Preschoolers in Home-Based Childcare: A Systematic Review. J Phys Act Health. 2015;12(6):879-89.

22. O'Brien KT, Vanderloo LM, Bruijns BA, Truelove S, Tucker P. Physical activity and sedentary time among preschoolers in centre-based childcare: a systematic review. Int J Behav Nutr Phys Act. 2018;15(1):117.

23. Hnatiuk JA, Salmon J, Hinkley T, Okely AD, Trost S. A review of preschool children's physical activity and sedentary time using objective measures. Am J Prev Med. 2014;47(4):487-97.

24. Hollis JL, Sutherland R, Williams AJ, Campbell L, Nathan N, Wolfenden L, et al. A systematic review and meta-analysis of moderate-to-vigorous physical activity levels in secondary school physical education lessons. Int J Behav Nutr Phys Act. 2017;14:52.

25. Hollis JL, Williams AJ, Sutherland R, Campbell L, Nathan N, Wolfenden L, et al. A systematic review and meta-analysis of moderate-to-vigorous physical activity levels in elementary school physical education lessons. Prev Med. 2015;86:34-54.

26. Ridgers ND, Stratton G, Fairclough SJ. Physical activity levels of children during school playtime. Sports Med. 2006;36(4):359-71.
27. Ridgers ND, Salmon J, Parrish AM, Stanley RM, Okely AD. Physical activity during school recess: a systematic review. Am J Prev Med. 2012;43(3):320-8.

28. Moher D, Liberati A, Tetzlaff J, Altman DG. The PRISMA Group. Preferred reporting items for systematic reviews and meta-analyses: the PRISMA Statement. PLoS Med. 2009;6(7):e1000097.

29. Stroup DF, Berlin JA, Morton SC, Olkin I, Williamson GD, Rennie D, et al Meta-analysis of observational studies in epidemiology: a proposal for reporting. Meta-analysis Of Observational Studies in Epidemiology (MOOSE) group. JAMA. 2000;283(15):2008-12.

30. Halpern R. After-school programs for low-income children: promise and challenges. Future Child. 1999;9(2):81-95.

31. Weaver RG, Brazendale K, Chandler JL, Turner-McGrievy GM, Moore JB, Huberty $J$, et al. First year physical activity findings from turn up the HEAT (Healthy Eating and Activity Time) in summer day camps. PloS One. 2017; 12(3):e0173791.

32. Beets MW, Bornstein D, Beighle A, Cardinal BJ, Morgan CF. Pedometermeasured physical activity patterns of youth: a 13-country review. Am J Prev Med. 2010;38(2):208-16.

33. Higgins JPT, Thomas J, Chandler J, Cumpston M, Li T, Page MJ, Welch VA (editors). Cochrane Handbook for Systematic Reviews of Interventions version 6.0 (updated July 2019). Cochrane, 2019. Available from www. training.cochrane.org/handbook. Accessed 18 January 2019.

34. Addy CL, Trilk JL, Dowda M, Byun W, Pate RR. Assessing preschool children's physical activity: how many days of accelerometry measurement. Pediatr Exerc Sci. 2014;26(1):103-9.

35. Andersen E, Borch-Jenssen J, Ovreas S, Ellingsen H, Jorgensen KA, Moser T. Objectively measured physical activity level and sedentary behavior in Norwegian children during a week in preschool. Prev Med Rep. 2017;7:130-5.

36. Barbosa SC, Coledam DHC, Stabelini Neto A, Elias RGM, de Oliveira AR. School environment, sedentary behavior and physical activity in preschool children. Rev Paul Pediatric. 2016;34(3):301-8.

37. Byun W, Beets MW, Pate RR. Sedentary Behavior in Preschoolers: How Many Days of Accelerometer Monitoring Is Needed? Int J Environ Res Public Health. 2015;12(10):13148-61.

38. Byun W, Blair SN, Pate RR. Objectively measured sedentary behavior in preschool children: comparison between Montessori and traditional preschools. Int J Behav Nutr Phys Act. 2013;10:2.

39. Copeland KA, Khoury JC, Kalkwarf HJ. Child Care Center Characteristics Associated With Preschoolers' Physical Activity. Am J Prev Med. 2016;50(4):470-9.

40. Dawson-Hahn EE, Fesinmeyer MD, Mendoza JA. Correlates of Physical Activity in Latino Preschool Children Attending Head Start. Pediatr Exerc Sci. 2015;27(3):372-9.

41. Delaney $S L$, Monsivais $P$, Johnson DB. Physical activity levels in family child care homes. J Phys Act Health. 2014;11(7):1362-6.

42. Ellis YG, Cliff DP, Janssen X, Jones RA, Reilly JJ, Okely AD. Sedentary time, physical activity and compliance with IOM recommendations in young children at childcare. Prev Med Rep. 2017;7:221-6.

43. Gagne C, Harnois I. The contribution of psychosocial variables in explaining preschoolers' physical activity. Health Psychol. 2013;32(6):657-65.

44. Henderson KE, Grode GM, O'Connell ML, Schwartz MB. Environmental factors associated with physical activity in childcare centers. Int J Behav Nutr Phys Act. 2015;12:43

45. Hesketh KR, McMinn AM, Ekelund U, et al. Objectively measured physical activity in four-year-old British children: a cross-sectional analysis of activity patterns segmented across the day. Int J Behav Nutr Phys Act. 2014;11:1

46. Hinkley T, Salmon J, Crawford D, Okely AD, Hesketh KD. Preschool and childcare center characteristics associated with children's physical activity during care hours: an observational study. Int J Behav Nutr Phys Act. 2016;13(1):117.

47. Kuzik N, Carson V. The association between physical activity, sedentary behavior, sleep, and body mass index z-scores in different settings among toddlers and preschoolers. BMC Pediatr. 2016;16:100.

48. LaRowe TL, Tomayko EJ, Meinen AM, Hoiting J, Saxler C, Cullen B, et al. Active Early: one-year policy intervention to increase physical activity among early care and education programs in Wisconsin. BMC Public Health. 2016;16:607

49. Loprinzi PD, Trost SG. Parental influences on physical activity behavior in preschool children. Prev Med. 2010;50(3):129-33.

50. Mazzucca S, Hales D, Evenson KR, Ammerman A, Tate DF, Berry DC, et al. Physical Activity Opportunities Within the Schedule of Early Care and Education Centers. J Phys Act Health. 2018;15(2):73-81. 
51. Moller NC, Christensen LB, Molgaard C, Ejlerskov KT, Pfeiffer KA, Michaelsen KF. Descriptive analysis of preschool physical activity and sedentary behaviors - a cross sectional study of 3-year-olds nested in the SKOT cohort. BMC Public Health. 2017:17(1):613

52. Neshteruk CD, Mazzucca S, Ostbye T, Ward DS. The physical environment in family childcare homes and children's physical activity. Child Care Health Dev. 2018;44(5):746-52.

53. O'Dwyer M, Fairclough SJ, Ridgers ND, Knowles ZR, Foweather L, Stratton G. Patterns of objectively measured moderate-to-vigorous physical activity in preschool children. J Phys Act Health. 2014;11(6):1233-8.

54. Olesen LG, Kristensen PL, Korsholm L, Froberg K. Physical activity in children attending preschools. Pediatrics. 2013;132(5):e1310-8.

55. O'Neill JR, Pfeiffer KA, Dowda M, Pate RR. In-school and Out-of-school Physical Activity in Preschool Children. J Phys Act Health. 2016;13(6):606-10.

56. Pagels P, Boldemann C, Raustorp A. Comparison of pedometer and accelerometer measures of physical activity during preschool time on 3- to 5-year-old children. Acta Paediatr. 2011;100(1):116-20.

57. Pate RR, O'Neill JR, Byun W, Mclver KL, Dowsa M, Brown WH. Physical activity in preschool children: comparison between Montessori and Traditional preschools. J Sch Health. 2014;84(11):716-21.

58. Rice KR, Trost SG. Physical activity levels among children attending family day care. J Nutr Educ Behav. 2014;46(3):197-202.

59. Shen B, Reinhart-Lee T, Janisse H, Brogan K, Danford C, Jen KL. African American preschool children's physical activity levels in Head Start. Res Q Exerc Sport. 2012;83(2):168-74.

60. Shen B, Alexander G, Milberger S, Jen C. An exploratory study of seasonality and preschoolers'physical activity engagement. J Phys Act Health. 2013; 10(7):993-9.

61. Sisson SB, Stoner J, Li J, Stephens L, Campbell JE, Lora KR, et al. Tribally Affiliated Child-Care Center Environment and Obesogenic Behaviors in Young Children. J Acad Nutr Diet. 2017;117(3):433-40.

62. Schuna JM. Loguori, Tucker J. Seasonal changes in preschoolers'sedentary time and physical activity at childcare. Int J Child Heal Nutr. 2016;5:17-24.

63. Schlechter CR, Rosenkranz RR, Fees BS, Dzewaltowski DA. Preschool daily patterns of physical activity driven by location and social context. J Sch Health. 2017;87(3):194-9.

64. Soini A, Watt A, Tammelin T, Soini M, Sääkslahti A, Poskiparta M. Comparing the physical activity patterns of 3-year-old Finnish and Australian children during childcare and homecare days. Balt J Heal Phys Act. 2014;6(3):171-82.

65. Sugiyama T, Okely AD, Masters JM, Moore GT. Attributes of Child Care Centers and Outdoor Play Areas Associated With Preschoolers' Physical Activity and Sedentary Behavior. Environ Behav. 2010;44(3):334-49.

66. Tucker P, Vanderloo LM, Burke SM, Irwin JD, Johnson AM. Prevalence and influences of preschoolers' sedentary behaviors in early learning centers: a cross-sectional study. BMC Pediatr. 2015:15:128.

67. Tandon PS, Saelens BE, Christakis DA. Active play opportunities at child care. Pediatrics. 2015;135(6):e1425-31.

68. Vale S, Santos R, Silva P, Soares-Miranda L, Mota J. Preschool children physical activity measurement: importance of epoch length choice. Pediatr Exerc Sci. 2009;21(4):413-20.

69. Vanderloo LM, Tucker $\mathrm{P}$, Johnson AM, van Zandvoort MM, Burke SM, Irwin JD. The influence of centre-based childcare on preschoolers' physical activity levels: a cross-sectional study. Int J Environ Res Public Health. 2014; 11(2):1794-802.

70. Vanderloo LM, Tucker P, Johnson AM, Burke SM, Irwin JD. Environmental Influences on Preschoolers' Physical Activity Levels in Various Early-Learning Facilities. Res Q Exerc Sport. 2015;86(4):360-70.

71. Vanderloo LM, Tucker P. Weekly trends in preschoolers' physical activity and sedentary time in childcare. Int J Environ Res Public Health. 2015;12(3):245464.

72. Van Cauwenberghe E, Wooller L, Mackay L, Cardon G, Oliver M. Comparison of Actical and activPAL measures of sedentary behaviour in preschool children. J Sci Med Sport. 2012;15(6):526-31.

73. Van Cauwenberghe E, De Craemer M, De Decker E, De Bourdeaudhuij I, Cardon G. The impact of a teacher-led structured physical activity session on preschoolers' sedentary and physical activity levels. J Sci Med Sport. 2013;16(5):422-6.

74. Van Cauwenberghe E, De Bourdeaudhuij I, Maes L, Cardon G. Efficacy and feasibility of lowering playground density to promote physical activity and to discourage sedentary time during recess at preschool: a pilot study. Prev Med. 2012;55(4):319-21.
75. Vanderloo LM, Tucker P. Physical activity and sedentary time among young children in full-day kindergarten: Comparing traditional and balanced day schedules. Health Educ J. 2016;76(1):29-37.

76. Ward S, Blanger M, Donovan D, Vatanparast $H$, Muhajarine N, Engler-Stringer $\mathrm{R}$, et al. Association between childcare educators' practices and preschoolers' physical activity and dietary intake: a cross-sectional analysis. BMJ Open. 2017;7(5):e013657.

77. Webster EK, Wadsworth DD, Robinson LE. Preschoolers' time on-task and physical activity during a classroom activity break. Pediatr Exerc Sci. 2015; 27(1):160-7.

78. Erinosho T, Hales D, Vaughn A, Mazzucca S, Ward DS. Impact of policies on physical activity and screen time practices in 50 child-care centers in North Carolina. J Phys Act Health. 2016;13(1):59-66.

79. Alhassan S, Nwaokelemeh O, Ghazarian M, Roberts J, Mendoza A, Shitole S. Effects of locomotor skill program on minority preschoolers' physical activity levels. Pediatr Exerc Sci. 2012;24(3):435-49.

80. Alhassan S, Nwaokelemeh O, Mendoza A, et al. Feasibility and Effects of Short Activity Breaks for Increasing Preschool-Age Children's Physical Activity Levels. J Sch Health. 2016;86(7):526-33.

81. Alhassan S, Sirard JR, Robinson TN. The effects of increasing outdoor play time on physical activity in Latino preschool children. Int J Pediatr Obes. 2007;2(3):153-8

82. Annesi JJ, Smith AE, Tennant GA. Effects of a cognitive-behaviorally based physical activity treatment for 4- and 5-year-old children attending US preschools. Int J Behav Med. 2013;20(4):562-6.

83. Annesi JJ, Smith AE, Tennant G. Cognitive-behavioural physical activity treatment in African-American pre-schoolers: effects of age, sex, and BMI. Paediatr Child Health. 2013;49(2):E128-32

84. Annesi JJ, Smith AE, Tennant GA. Effects of the Start For Life treatment on physical activity in primarily African American preschool children of ages 35 years. Psychol Health Med. 2013;18(3):300-9.

85. Pate RR, Brown WH, Pfeiffer KA, Howie EK, Saunders RP, Addy CL, et al. An intervention to increase physical activity in children: a randomized controlled trial with 4-year-olds in preschools. Am J Prev Med. 2016;51(1): $12-22$.

86. Razak LA, Yoong SL, Wiggers J, Morgan PJ, Jones J, Finch M, et al. Impact of scheduling multiple outdoor free-play periods in childcare on child moderate-to-vigorous physical activity: a cluster randomised trial. Int J Behav Nutr Phys Act. 2018;15(1):34.

87. Tucker $\mathrm{P}$, Vanderloo LM, Johnson AM, Burke SM, Irwin JD, Gaston A, et al. Impact of the Supporting Physical Activity in the Childcare Environment (SPACE) intervention on preschoolers' physical activity levels and sedentary time: a single-blind cluster randomized controlled trial. Int J Behav Nutr Phys Act. 2017;14(1):120

88. Bonis M, Loftin M, Ward D, Tseng TS, Clesi A, Sothern M. Improving physical activity in daycare interventions. Child Obes. 2014;10(4):334-41.

89. Goldfield GS, Harvey ALJ, Grattan KP, Temple V, Naylor PJ, Alberga AS, et al. Effects of Child Care Intervention on Physical Activity and Body Composition. Am J Prev Med. 2016:51(2):225-31.

90. Carson V, Clark D, Ogden N, Harber V, Kuzik N. Short-term influence of revised provincial accreditation standards on physical activity, sedentary behavior, and weight status in Alberta, Canada Child Care Centers. Early Child Educ J. 2015:43(6):459-65.

91. Nielsen G, Bugge A, Hermansen B, Svensson J, Andersen LB. School playground facilities as a determinant of children's daily activity: a crosssectional study of Danish primary school children. J Phys Act Health. 2012; 9(1):104-14

92. Da Costa BG, da Silva KS, George AM, de Assis MA. Sedentary behavior during school-time: Sociodemographic, weight status, physical education class, and school performance correlates in Brazilian schoolchildren. J Sci Med Sport. 2017;20(1):70-4.

93. Cinemre SA. Physical activity intensities during school time in healthy prepubertal boys and BMI. Turk J Pediatr. 2015;57(6):572-7.

94. Lin C-Y, Su C-T, Ma H-I. Physical Activity Patterns and Quality of Life of Overweight Boys: A Preliminary Study. Hong Kong J Occup Ther. 2012;22(1):31-7.

95. Suzuki I, Okuda M, Tanaka M, Inoue S, Tanaka S, Tanaka C. Variability in school children's activity occurs in the recess and before-school periods. Pediatr Int. 2018:60(8):727-34.

96. Ching Ting JL, Mukherjee S, Yong Hwa MC. Physical Activity and Sedentary Behavior Patterns of Singaporean Adolescents. J Phys Act Health. 2015;12(9): 1213-20. 
97. Zimmo L, Faroog A, Almudahka F, Ibrahim I, Al-Kuwari MG. School-time physical activity among Arab elementary school children in Qatar. BMC Pediatr. 2017;17(1):76.

98. Aadland E, Andersen LB, Ekelund U, Anderssen SA, Resaland GK. Reproducibility of domain-specific physical activity over two seasons in children. BMC Public Health. 2018;18(1):821.

99. Aibar A, Bois JE, Zaragoza Casterad J, Generelo E, Paillard T, Fairclough S Weekday and weekend physical activity patterns of French and Spanish adolescents. Eur J Sport Sci. 2014;14(5):500-9.

100. Andersen HB, Klinker CD, Toftager M, Pawlowski CS, Schipperijn J. Objectively measured differences in physical activity in five types of schoolyard area. Landsc Urban Plan. 2015;134:83-92.

101. De Baere S, Philippaerts R, De Martelaer K, Lefevre J. Associations Between Objectively Assessed Components of Physical Activity and Health-Related Fitness in 10- to 14-Year-Old Children. J Phys Act Health. 2016;13(9):9931001.

102. Bailey DP, Fairclough SJ, Savory LA, Denton SJ, Pang D, Deane CS, et al. Accelerometry-assessed sedentary behaviour and physical activity levels during the segmented school day in 10-14-year-old children: the HAPPY study. Eur J Pediatr. 2012;171(12):1805-13.

103. Carlin A, Murphy MH, Nevill A, Gallagher AM. Effects of a peer-led Walking In ScHools intervention (the WISH study) on physical activity levels of adolescent girls: a cluster randomised pilot study. Trials. 2018;19(1):31.

104. Decelis A, Jago R, Fox KR. Physical activity, screen time and obesity status in a nationally representative sample of Maltese youth with international comparisons. BMC Public Health. 2014;14(1):664.

105. Decelis A, Jago R, Fox KR. Objectively assessed physical activity and weight status in Maltese 11-12 year-olds. Eur J Sport Sci. 2014;14(Suppl 1):S257-66.

106. Fairclough SJ, Butcher ZH, Stratton G. Whole-day and segmented-day physical activity variability of northwest England school children. Prev Med. 2007;44(5):421-5.

107. Fairclough SJ, Beighle A, Erwin H, Ridgers ND. School day segmented physical activity patterns of high and low active children. BMC Public Health. 2012;12:406.

108. Guinhouya BC, Lemdani M, Vilhelm C, Hubert H, Apété G, Durocher A. How school time physical activity is the "big one" for daily activity among school children. J Phys Act Health. 2009;6(4):510-9.

109. Hamer M, Aggio D, Knock G, Kipps C, Shankar A, Smith L. Effect of major school playground reconstruction on physical activity and sedentary behaviour: Camden active spaces. BMC Public Health. 2017;17(1):552.

110. Harding SK, Page AS, Falconer C, Cooper AR. Longitudinal changes in sedentary time and physical activity during adolescence. Int J Behav Nutr Phys Act. 2015;12:44

111. Harrington DM, Gillison F, Broyles ST, Chaput JP, Fogelholm M, Hu G, et al. Household-level correlates of children's physical activity levels in and across 12 countries. Obesity. 2016;24(10):2150-7.

112. Kriemler S, Zahner L, Schindler C, Meyer U, Hartmann T, Hebestreit $H$, et al, Effect of school based physical activity programme (KISS) on fitness and adiposity in primary schoolchildren: cluster randomised controlled trial. BMJ. 2010;340:c785

113. Magnusson KT, Sigurgeirsson I, Sveinsson T, Johannsson E. Assessment of a two-year school-based physical activity intervention among 7-9-year-old children. Int J Behav Nutr Phys Act. 2011:8:138

114. Martin R, Murtagh E. active classrooms: a cluster randomized controlled trial evaluating the effects of a movement integration intervention on the physical activity levels of primary school children. J Phys Act Health. 2017; 14(4):290-300.

115. Mooses K, Maestu J, Riso EM, Hannus A, Mooses M, Kaasik P, et al. Different methods yielded two-fold difference in compliance with physical activity guidelines on school days. PloS One. 2016;11(3):e0152323.

116. Morton KL, Corder K, Suhrcke M, Harrison F, Jones AP, van Sluijs EM, et al. School polices, programmes and facilities, and objectively measured sedentary time, LPA and MVPA: associations in secondary school and over the transition from primary to secondary school. Int J Behav Nutr Phys Act 2016;13:54.

117. Nilsson A, Anderssen SA, Andersen LB, Froberg K, Riddoch C, Sardinha LB, et al. Between- and within-day variability in physical activity and inactivity in 9- and 15-year-old European children. Scand J Med Sci Sports. 2009;19(1): $10-8$.

118. Noonan RJ, Boddy LM, Kim Y, Knowles ZR, Fairclough SJ. Comparison of children's free-living physical activity derived from wrist and hip raw accelerations during the segmented week. J Sports Sci. 2017;35(21): 2067-72.

119. Pau M, Corona F, Leban B, Piredda S, Vacca MM, Mura G. Influence of schoo schedules on physical activity patterns in primary school children: A case study in Italy. J Phys Act Health. 2017;14(7):501-5.

120. Pearce M, Saunders DH, Allison P, Turner AP. Indoor and outdoor contextspecific contributions to early adolescent moderate to vigorous physical activity as measured by combined diary, accelerometer, and GPS. J Phys Act Health. 2018;15(1):40-5.

121. Pizarro AN, Schipperijn J, Ribeiro JC, Figueiredo A, Mota J, Santos MP. Gender differences in the domain-specific contributions to moderate-tovigorous physical activity, accessed by GPS. J Phys Act Health. 2017;14(6): 474-8.

122. Pulsford RM, Griew P, Page AS, Cooper AR, Hillsdon MM. Socioeconomic position and childhood sedentary time: evidence from the PEACH project. Int J Behav Nutr Phys Act. 2013;10:105.

123. Ramirez-Rico E, Hilland TA, Foweather L, Fernandez-Garcia E, Fairclough SJ. Weekday and weekend patterns of physical activity and sedentary time among Liverpool and Madrid youth. Eur J Sport Sci. 2014;14(3):287-93.

124. Resaland GK, Aadland E, Moe VF, Aadland KN, Skrede T, Stavnsbo M, et al. Effects of physical activity on schoolchildren's academic performance: The Active Smarter Kids (ASK) cluster-randomized controlled trial. Prev Med. 2016;91:322-8.

125. Ridgers N, Graves LEF, Foweather L, Tratton G. Examining influences on boy's and girls' physical activity patterns: The A-CLASS project. Pediatr Exerc Sci. 2010;22(4):638-50

126. Silva DR, Minderico CS, Pinto F, Collings PJ, Cyrino ES, Sardinha LB. Impact of a classroom standing desk intervention on daily objectively measured sedentary behavior and physical activity in youth. J Sci Med Sport. 2018; 21(9):919-24.

127. Taylor SL, Curry WB, Knowles ZR, Noonan RJ, McGrane B, Fairclough SJ. Predictors of segmented school day physical activity and sedentary time in children from a Northwest England low-income community. Int J Environ Res Public Health. 2017;14(5):534.

128. Van Stralen MM, Yildirim M, Wulp A, te Velde SJ, Verloigne M, Doessegger A et al. Measured sedentary time and physical activity during the school day of European 10- to 12-year-old children: the ENERGY project. J Sci Med Sport. 2014;17(2):201-6.

129. Sigmund E, Sigmundova D, Hamrik Z, Madarasova GA. Does participation in physical education reduce sedentary behaviour in school and throughout the day among normal-weight and overweight-to-obese Czech children aged 9-11 years? Int J Environ Res Public Health. 2014;11(1):1076-93.

130. Sprengeler O, Wirsik N, Hebestreit A, Herrmann D, Ahrens W. Domainspecific self-reported and objectively measured physical activity in children. Int J Environ Res Public Health. 2017;14(3):242.

131. Steele RM, Van Sluijs EM, Sharp SJ, Landsbaugh JR, Ekelund U, Griffin SJ. An investigation of patterns of children's sedentary and vigorous physical activity throughout the week. Int J Behav Nutr Phys Act. 2010;7:88. https:// ijbnpa.biomedcentral.com/articles/10.1186/1479-5868-7-88.

132. Vanhelst J, Beghin L, Duhamel A, De Henauw S, Molnar D, VicenteRodriguez $\mathrm{G}$, et al. Relationship between school rhythm and physical activity in adolescents: the HELENA study. J Sports Sci. 2017;35(16): 1666-73.

133. Van Sluijs EM, Jones NR, Jones AP, Sharp SJ, Harrison F, Griffin SJ. Schoollevel correlates of physical activity intensity in 10-year-old children. Int J Pediatr Obes. 2011;6(2-2):e574-81.

134. Verloigne M, Berntsen S, Ridgers ND, Cardon G, Chinapaw M, Altenburg T, et al. The UP4FUN intervention effect on breaking up sedentary time in 10to 12-year-old Belgian children: The ENERGY-Project. Pediatr Exerc Sci. 2015; 27(2):234-42.

135. Bershwinger T, Brusseau TA. The impact of classroom activity breaks on the school-day physical activity of rural children. Int J Exerc Sci. 2013;6(2):134-43.

136. Brittin J, Frerichs L, Sirard JR, Wells NM, Myers BM, Garcia J, et al. Impacts of active school design on school-time sedentary behavior and physical activity: A pilot natural experiment. PloS One. 2017;12(12):e0189236.

137. Brusseau TA, Burns RD, Fu Y. Contextual factors related to physical activity during daily middle school physical education. J Sci Med Sport. 2016;19(9): 733-7.

138. Burns RD, Brusseau TA, Fu Y, Hannon JC. Establishing school day pedometer step count cut-points using ROC curves in low-income children. Prev Med. 2016:86:117-22. 
139. Burns RD, Brusseau TA, Fu Y, Zhang P. Development of Step-Count Cut Points for School-Day Vigorous Physical Activity. BioMed Res Int. 2018;2018: 9717848.

140. Carlson JA, Sallis JF, Norman GJ, McKenzie TL, Kerr J, Arredondo EM, et al. Elementary school practices and children's objectively measured physical activity during school. Prev Med. 2013:57(5):591-5.

141. Carlson JA, Engelberg JK, Cain KL, Conway TL, Mignano AM, Bonilla EA, et al. Implementing classroom physical activity breaks: Associations with student physical activity and classroom behavior. Prev Med. 2015;81:67-72.

142. Carlson JA, Mitchell TB, Saelens BE, Staggs VS, Kerr J, Frank LD, et al. Withinperson associations of young adolescents' physical activity across five primary locations: is there evidence of cross-location compensation? Int J Behav Nutr Phys Act. 2017;14(1):50.

143. Carson RL, Castelli DM, Pulling Kuhn AC, et al. Impact of trained champions of comprehensive school physical activity programs on school physical activity offerings, youth physical activity and sedentary behaviors. Prev Med. 2014:69(Suppl 1):S12-9.

144. Centeio EE, McCaughtry N, Gutuskey L, Garn AC, Somers C, Shen B, et al. Chapter 8 Physical Activity Change Through Comprehensive School Physical Activity Programs in Urban Elementary Schools. J Teach Phys Educ. 2014; 33(4):573-91.

145. Cohen D, Scott M, Wang FZ, McKenzie TL, Porter D. School design and physical activity among middle school girls. J Phys Act Health. 2008;5(5): 719-31

146. Cradock AL, Barrett JL, Carter J, McHugh A, Sproul J, Russo ET, et al. Impact of the Boston active school day policy to promote physical activity among children. Am J Health Promot. 2014;28(3 Suppl):S54-64.

147. Gao Z, Chen S, Huang CC, Stodden DF, Xiang P. Investigating elementary school children's daily physical activity and sedentary behaviours during weekdays. J Sports Sci. 2017;35(1):99-104

148. Goh TL, Hannon J, Webster CA, Podlog LW, Brusseau T, Newton M. Chapter 7 Effects of a Classroom-Based Physical Activity Program on Children's Physical Activity Levels. J Teach Phys Educ. 2014;33(4):558-72.

149. Herrick H, Thompson H, Kinder J, Madsen KA. Use of SPARK to promote after-school physical activity. J Sch Health. 2012;82(10):457-61.

150. Hubbard K, Economos CD, Bakun P, Boulos R, Chui K, Mueller MP, et al. Disparities in moderate-to-vigorous physical activity among girls and overweight and obese schoolchildren during school- and out-of-school time. Int J Behav Nutr Phys Act. 2016;13:39.

151. Kim Y, Lochbaum M. Objectively measured physical activity levels among ethnic minority children attending school-based afterschool programs in a high-poverty neighborhood. J Sports Sci Med. 2017;16(3):350-6.

152. Kulik NL, Somers CL, Thomas E, Martin JJ, Centeio EE, Garn AC, et al. Source and Type of Support for In-School Physical Activity: Differential Patterns for Demographic Subgroups. Am J Health Educ. 2015;46(5):301-9.

153. Kwon S, Burns TL, Levy SM, Janz KF. Breaks in sedentary time during childhood and adolescence: lowa bone development study. Med Sci Sports Exerc. 2012:44(6):1075-80.

154. Lee JE, Stodden DF, Gao Z. Young Children's Energy Expenditure and Moderate-to-vigorous Physical Activity on Weekdays and Weekends. J Phys Act Health. 2016;13(9):1013-6.

155. Long MW, Sobol AM, Cradock AL, Subramanian SV, Blendon RJ, Gortmaker SL. School-day and overall physical activity among youth. Am J Prev Med. 2013:45(2):150-7.

156. Madsen K, Thompson H, Adkins A, Crawford Y. School-community partnerships: a cluster-randomized trial of an after-school soccer program. JAMA Pediatr. 2013;167(4):321-6.

157. Madsen K, Linchey J, Gerstein D, Ross M, Myers E, Brown K, et al. Energy Balance 4 Kids with Play: Results from a Two-Year Cluster-Randomized Trial. Child Obes. 2015;11(4):375-83.

158. Nettlefold L, McKay HA, Warburton DE, McGuire KA, Bredin SS, Naylor PJ. The challenge of low physical activity during the school day: at recess, lunch and in physical education. Br J Sports Med. 2011;45(10):813-9.

159. Yli-Piipari S, Kulmala JS, Jaakkola T, Hakonen H, Fish JC, Tammelin T. Objectively Measured School Day Physical Activity Among Elementary Students in the United States and Finland. J Phys Act Health. 2016;13(4):440-6.

160. Kneeshaw-Price S, Saelens BE, Sallis JF, Glanz K, Frank LD, Kerr J, et al. Children's objective physical activity by location: why the neighborhood matters. Petriatr Exerc Sci. 2013:25(3):468-86.
161. Rainham DG, Bates CJ, Blanchard CM, Dummer TJ, Kirk SF, Shearer CL. Spatial classification of youth physical activity patterns. Am J Prev Med. 2012;42(5):e87-96

162. Taverno Ross SE, Dowda M, Beets MW, Pate RR. Physical activity behavior and related characteristics of highly active eight-grade girls. J Adolesc Health. 2013;52(6):745-51.

163. Sayers SP, LeMaster JW, Thomas IM, Petroski GF, Ge B. A walking school bus program: impact on physical activity in elementary school children in Columbia. Missouri. Am J Prev Med. 2012;43(5 Suppl 4):S384-9.

164. Weaver RG, Crimarco A, Brussseau TA, Webster CA, Burns RD, Hannon JC. Accelerometry-devired physical activity of first throuth third grade children during the segmented school day. J Phys Act Health. 2016; 86(10):726-33.

165. Weaver RG, Webster CA, Beets MW, Brazendale K, Schisler L, Aziz M. An intervention to increase students' physical activity: a 2-year pilot study. Am J Prev Med. 2018;55(1):e1-e10.

166. Weaver RG, Webster CA, Egan C, Campos CMC, Michael RD, Vazou S. Partnerships for active children in elementary schools: outcomes of a 2-year pilot study to increase physical activity during the school day. Am J Health Promot. 2018:32(3):621-30.

167. Wells NM, Myers BM, Henderson CR Jr. School gardens and physical activity: a randomized controlled trial of low-income elementary schools. Prev Med. 2014;69(Suppl 1):S27-33.

168. Schneider M, Schmalbach P, Godkin S. Impact of a personalized versus moderate-intensity exercise prescription: a randomized controlled trial. J behav Med. 2017:40(2):239-48.

169. Siahpush M, Huberty JL, Beighle A. Does the effect of a school recess intervention on physical activity vary by gender or race? results from the ready for recess pilot study. J Public Health Manag Pract. 2012;18(5):416-22.

170. Lewis L, Maher C, Katzmarzyk P, Olds T. Individual and school-level socioeconomic gradients in physical activity in Australian school children. J Sch Health. 2016:86(2):105-12.

171. Strugnell C, Turner K, Malakellis M, Hayward J, Foster C, Millar L, et al. Composition of objectively measured physical activity and sedentary behaviour participation across the school-day, influence of gender and weight status: cross-sectional analyses among disadvantaged Victorian school children. BMJ Open. 2016;6(9):e011478.

172. Rush E, Coppinger T, Obolonkin V, Hinckson E, McGrath L, McLennan S, et al. Use of pedometers to identify less active children and time spent in moderate to vigorous physical activity in the school setting. J Sci Med Sport. 2012;15(3):226-30.

173. Stewart T, Duncan S, Schipperijn J. Adolescents who engage in active school transport are also more active in other contexts: A space-time investigation. Health Place. 2017:43:25-32.

174. Engelen L, Bundy AC, Naughton G, Simpson JM, Bauman A, Ragen J, et al. Increasing physical activity in young primary school children--it's child's play: a cluster randomised controlled trial. Prev Med. 2013:56(5):319-25.

175. Farmer VL, Williams SM, Mann Jl, Schofield G, McPhee JC, Taylor RW. The effect of increasing risk and challenge in the school playground on physical activity and weight in children: a cluster randomised controlled trial (PLAY). Int J Obes. 2017:41(5):793-800.

176. Sutherland RL, Nathan NK, Lubans DR, Cohen K, Davies LJ, Desmet C, et al. An RCT to Facilitate Implementation of School Practices Known to Increase Physical Activity. Am J Prev Med. 2017;53(6):818-28.

177. Riley N, Lubans DR, Holmes K, Morgan PJ. Findings from the EASY minds cluster randomized controlled trial: evaluation of a physical activity integration program for mathematics in primary schools. J Phys Act Health. 2016;13(2):198-206.

178. Abbott RA, Straker LM, Mathiassen SE. Patterning of children's sedentary time at and away from school. Obesity (Silver Spring). 2013;21(1):e131-3.

179. Carson V, Cliff DP, Janssen X, Okely AD. Longitudinal levels and bouts of sedentary time among adolescent girls. BMC Pediatr. 2013;13:173.

180. Taylor RW, Farmer VL, Cameron SL, Meredith-Jones K, Williams SM, Mann Jl. School playgrounds and physical activity policies as predictors of school and home time activity. Int J Behav Nutr Phys Act. 2011;8:38. https://ijbnpa. biomedcentral.com/articles/10.1186/1479-5868-8-38.

181. Wilson AN, Olds T, Lushington K, Parvazian S, Dollman J. Active School Lesson Breaks Increase Daily Vigorous Physical Activity, but Not Daily Moderate to Vigorous Physical Activity in Elementary School Boys. Pediatr Exerc Sci. 2017:29(1):145-52. 
182. Arundell L, Ridgers ND, Veitch J, Salmon J, Hinkley T, Timperio A. 5-year changes in afterschool physical activity and sedentary behavior. Am J Prev Med. 2013:44(6):605-11.

183. Beets MW, Glenn Weaver R, Brazendale K, Turner-McGrievy G, Saunders RP, Moore JB, et al. Statewide dissemination and implementation of physical activity standards in afterschool programs: two-year results. BMC Public Health. 2018;18(1):819

184. Beets MW, Shah R, Weaver RG, Huberty J, Beighle A, Moore JB. Physical activity in after-school programs: comparison with physical activity policies. J Phys Act Health. 2015;12(1):1-7.

185. Beets MW, Weaver RG, Turner-McGrievy G, Huberty J, Ward DS, Pate RR, et al. Making policy practice in afterschool programs: a randomized controlled trial on physical activity changes. Am J Prev Med. 2015;48(6):694-706.

186. Beets MW, Beighle A, Bottai M, Rooney L, Tilley F. Pedometer-determined stepcount guidelines for afterschool programs. J Phys Act Health. 2012;9(1):71-7.

187. Beets MW, Rooney L, Tilley F, Beighle A, Webster C. Evaluation of policies to promote physical activity in afterschool programs: are we meeting current benchmarks? Prev Med. 2010;51(3-4):299-301.

188. Beets MW, Weaver RG, Moore JB, Turner-McGrievy G, Pate RR, Webster C, et al. From policy to practice: strategies to meet physical activity standards in YMCA afterschool programs. Am J Prev Med. 2014;46(3):281-8.

189. Dzewaltowski DA, Rosenkranz RR, Geller KS, Coleman KJ, Welk GJ, Hastmann TJ, et al. HOP'N after-school project: an obesity prevention randomized controlled trial. Int J Behav Nutr Phys Act. 2010;7:90.

190. Huberty JL, Dinkel DM, Beets MW. Evaluation of GoGirlGo!: A practitioner based program to improve physical activity. BMC Public Health. 2014;14:118.

191. Trost SG, Rosenkranz RR, Dzewaltowski D. Physical activity levels among children attending after-school programs. Med Sci Sports Exerc. 2008;40(4):622-9.

192. Gesell SB, Sommer EC, Lambert EW, Vides de Andrade AR, Whitaker L, Davis L, Beech BM, Mitchell SJ, Arinze N, Neloms S, Ryan CK, Barkin SL. Comparative effectiveness of after-school programs to increase physical activity. J Obes. 2013;2013:576821. https:/pubmed.ncbi.nlm.nih.gov/23984052/.

193. Cradock AL, Barrett JL, Giles CM, et al. Promoting physical activity with the out of school nutrition and physical activity (OSNAP) initiative: a clusterrandomized controlled trial. JAMA Pediatr. 2016;170(2):155-62.

194. Beets MW, Morgan CF, Banda JA, Bornstein D, Byun W, Mitchell J, Munselle $L$, et al. Convergent validity of pedometer and accelerometer estimates of moderate-to-vigorous physical activity of youth. J Phys Act Health. 2011; 8(Suppl 2):s295-305.

195. Baker BL, McGregor A, Johnson LG, Taylor M. Summer day camp attendance facilitates some children meeting physical activity recommendations: Differences by gender and weight status. J Appl Biobehav Res. 2017;22(4):e12097.

196. Barnett EY, Ridker PM, Okechukwu CA, Barrett JL, Gortmaker SL. Children's physical activity levels in a sports-oriented summer day camp. J Hum Sport Exerc. 2018;13(2):430-42

197. Guagliano JM, Lonsdale C, Kolt GS, Rosenkranz RR, George ES. Increasing girls' physical activity during a short-term organized youth sport basketball program: A randomized controlled trial. J Sci Med Sport. 2015;18(4):412-7.

198. Behrens TK, Miller DJ, Schuna JM Jr, Liebert ML. Physical activity intensity, lesson context, and teacher interactions during an unstructured afterschool physical activity program. J Sch Health. 2015;85(12):880-5.

199. Behrens TK, Schuna JM Jr, Liebert ML, Davis SK, Rice KR. Evaluation of an unstructured afterschool physical activity programme for disadvantaged youth. J Sports Sci. 2016;34(22):2140-4.

200. Fenton SA, Duda JL, Barrett T. The contribution of youth sport football to weekend physical activity for males aged 9 to 16 years: variability related to age and playing position. Pediatr Exerc Sci. 2015;27(2):208-18.

201. Guagliano JM, Rosenkranz RR, Kolt GS. Girls' physical activity levels during organized sports in Australia. Med Sci Sports Exerc. 2013;45(1):116-22.

202. Guagliano JM, Updyke NJ, Rodicheva NV, et al. Influence of Session Context on Physical Activity Levels Among Russian Girls During a Summer Camp. Res Q Exerc Sport. 2017:88(3):352-7.

203. Leek D, Carlson JA, Cain KL, et al. Physical activity during youth sports practices. Arch Pediatr Adolesc Med. 2011;165(4):294-9.

204. Lopez Castillo MA, Carlson JA, Cain KL, et al. Dance class structure affects youth physical activity and sedentary behavior: a study of seven dance types. Res Q Exerc Sport. 2015;86(3):225-32.

205. Rosenkranz RR, Welk GJ, Dzewaltowski DA. Environmental correlates of objectively measured physical activity and sedentary behavior in afterschool recreation sessions. J Phys Act Health. 2011;8(s2):S214-21.
206. Schlechter CR, Rosenkranz RR, Milliken GA, Dzewaltowski DA. Physical activity levels during youth sport practice: does coach training or experience have an influence? J Sports Sci. 2017;35(1):22-8.

207. Cain KL, Gavand KA, Conway TL, et al. Physical activity in youth dance classes. Pediatrics. 2015;135(6):1066-73.

208. Cohen A, McDonald S, Mclver K, Pate R, Trost S. Assessing physical activity during youth sport: the observational system for recording activity in children: youth sports. Pediatr Exerc Sci. 2014;26(2):203-9.

209. O'Neill JR, Pate RR, Beets MW. Physical activity levels of adolescent girls during dance classes. J Phys Act Health. 2012;9(3):382-8.

210. Ridley K, Zabeen S, Lunnay BK. Children's physical activity levels during organised sports practices. J Sci Med Sport. 2018;21(9):930-4.

211. Schuna JM Jr, Lauersdorf RL, Behrens TK, Liguori G, Liebert ML. An objective assessment of children's physical activity during the Keep It Moving! afterschool program. J Sch Health. 2013;83(2):105-11.

212. Sacheck JM, Nelson T, Ficker L, Kafka T, Kuder J, Economos CD. Physical activity during soccer and its contribution to physical activity recommendations in normal weight and overweight children. Pediatr Exerc Sci. 2011;23(2):281-92

213. Smith MP, Berdel D, Nowak D, Heinrich J, Schulz H. Physical activity levels and domains assessed by accelerometry in German adolescents from GINIplus and LISAplus. PLoS One. 2016:11(3):e0152217.

214. Pratt CA, Loria CM, Arteaga SS, et al. A systematic review of obesity disparities research. Am J Prev Med. 2017;53(1):113-22.

215. Bleich SN, Vercammen KA, Zatz LY, Frelier JM, Ebbeling CB, Peeters A. Interventions to prevent global childhood overweight and obesity: a systematic review. Lancet Diabetes Endocrinol. 2018;6(4):332-46.

216. National Physical Activity Plan Alliance. The 2018 United States Report Card on Physical Activity for Children and Youth. Washington, DC: National Physical Activity Plan Alliance; 2018.

217. Aubert S, Barnes JD, Abdeta C, et al. Global matrix 3.0 physical activity report card grades for children and youth: results and analysis from 49 countries. J Phys Act Health. 2018:15(S2):S251-73.

218. Institute of Medicine. Early Childhood Obesity Prevention Policies. Washington, DC: The National Academies Press; 2011.

219. Tremblay MS, Carson V, Chaput JP, et al. Canadian 24-hour movement quidelines for children and youth: an integration of physical activity, sedentary behaviour, and sleep. Appl Physiol Nutr Metab. 2016;41(6 Suppl 3):S311-27.

220. Okely AD, Ghersi D, Hesketh KD, et al. A collaborative approach to adopting/ adapting guidelines - The Australian 24-hour movement guidelines for the early years (birth to 5 years): an integration of physical activity, sedentary behavior, and sleep. BMC Public Health. 2017:17(Suppl 5):869.

221. New Zealand Ministry of Health. 2017. Sit less, move more, sleep well: active play guidelines for under-fives. Wellington, New Zealand. Avaliable from https://www.health.govt.nz/publication/sit-less-move-more-sleep-well-activeplay-guidelines-under-fives.

222. World Health Organization. Guidelines on Physical Activity, Sedentary Behaviour and Sleep for Children Under 5 Years of Age. Geneva, Switzerland: World Health Organization; 2019. Avaliable from: https://www.who.int/ publications-detail/guidelines-on-physical-activity-sedentary-behaviour-andsleep-for-children-under-5-years-of-age. Accessed 14 March 2020.

223. Wiecha JL, Hall G, Gannett E, Roth B. National AfterSchool Association Standards for Healthy Eating and Physical Activity. 2011. Avaliable from: http://www.niost.org/StandardsandGuidelines/national-afterschoolassociation-standards-for-healthy-eating-and physical-activity-in-out-ofschool-time-programs Accessed 15 March 2020

224. Wickel EE, Eisenmann JC. Contribution of youth sport to total daily physical activity among 6- to 12-yr-old boys. Med Sci Sports Exerc. 2007;39(9):1493-500.

\section{Publisher's Note}

Springer Nature remains neutral with regard to jurisdictional claims in published maps and institutional affiliations. 